Algal Research

November 2017, Volume 27 Pages 177-189

http://dx.doi.org/10.1016/i.algal.2017.09.003

http://archimer.ifremer.fr/doc/00399/51074/

(C) 2017 Elsevier B.V. All rights reserved.

\title{
Effects of growth phase and nitrogen limitation on biochemical composition of two strains of Tisochrysis lutea
}

\author{
Da Costa Fiz ${ }^{1}$, Le Grand Fabienne ${ }^{2}$, Quéré Claudie ${ }^{1}$, Bougaran Gael ${ }^{3}$, Cadoret Jean-Paul ${ }^{3}$, \\ Robert Rene ${ }^{1,4}$, Soudant Philippe ${ }^{2, *}$
}

\author{
${ }^{1}$ Ifremer, Laboratoire des Sciences de l'Environnement Marin (UMR 6539, LEMAR), 29280 Plouzané, \\ France \\ ${ }^{2}$ Laboratoire des Sciences de l'Environnement Marin (UMR 6539, LEMAR), IUEM/UBO, Technopole \\ Brest Iroise, Plouzané, France \\ ${ }^{3}$ Ifremer, Laboratoire Physiologie et Biotechnologies des Algues, Rue de l'île d'Yeu, BP 21105, 44311 \\ Nantes cedex 3, France \\ ${ }^{4}$ Ifremer, Unité Littoral, Centre Bretagne, ZI de la Pointe du Diable - CS 10070, 29280 Plouzané, \\ France \\ * Corresponding author : Philippe Soudant, email address : soudant@univ-brest.fr
}

\begin{abstract}
:
Standard and mutant Tisochrysis lutea strains were grown in batch culture for 10 days under nitrogen (N)-replete and $\mathrm{N}$-reduced conditions to determine the effects of $\mathrm{N}$ supply in culture medium and growth phase on microalgal physiology and biochemistry. These two T. lutea strains were compared in terms of growth, morphology, associated free-living bacterial community, viability, intracellular lipid content (as measured by Bodipy staining), chlorophyll autofluorescence, and biochemical composition, with a focus on lipid class and fatty acid compositions. The standard strain $(\mathbf{T})$ reached higher cell counts regardless of $\mathrm{N}$ supply in culture medium. In both $T$. lutea strains, microalgal final cell density was significantly lower in N-reduced medium. Carbohydrates were enhanced at stationary phase in both strains, regardless of $\mathrm{N}$ supply. The oleaginous strain $(\mathbf{T}+)$ accumulated triacylglycerols; whereas, the standard strain $\mathbf{T}$ accumulated alkenones as reserve lipids, especially in $\mathrm{N}$-reduced medium and stationary phase. Each T. lutea strain exhibited an intrinsic specific FA profile in neutral lipids (NL) and, to a lesser extent, in polar lipids (PL) independent of $\mathrm{N}$ supply and growth phase. $\mathbf{T}+$ contained more saturated and monounsaturated fatty acids (especially 14:0 and 18:1n-9), but less polyunsaturated fatty acids (18:4n-3 and 22:6n-3) than T. Overall, growth phase induced more changes in fatty acid profiles of both T. lutea strains in NL and PL than N supply in culture medium.
\end{abstract}




\section{Highlights}

- We studied nitrogen availability and harvesting stage in Tisochrysis lutea. The oleaginous strain $(T+)$ accumulated triacylglycerols. The standard strain $T$ accumulated alkenones as reserve lipids. - Each strain exhibited an intrinsic fatty acid profile. Fatty acid profiles in both strains were more sensitive to harvesting stage.

\section{Abbreviations}

\begin{tabular}{|c|c|}
\hline$A L$ & alcohols \\
\hline ALK & alkenones \\
\hline ANOSIM & analysis of similarities \\
\hline DW & dry weight \\
\hline EFA & essential fatty acid \\
\hline $\mathrm{FA}$ & fatty acid \\
\hline FAME & fatty acid methyl esters \\
\hline $\mathrm{FCM}$ & flow cytometry \\
\hline FFA & free fatty acids \\
\hline FSC & forward scatter \\
\hline GE & glyceryl ethers \\
\hline $\mathrm{HC}$ & hydrocarbons \\
\hline L & logarithmic phase \\
\hline MUFA & monounsaturated fatty acids \\
\hline $\mathrm{N}$ & nitrogen \\
\hline $\mathrm{NL}$ & neutral lipids \\
\hline PL & polar lipids \\
\hline PUFA & polyunsaturated fatty acids \\
\hline $\mathrm{S}$ & stationary phase \\
\hline SFA & saturated fatty acids \\
\hline SIMPER & similarity percentage analysis \\
\hline SSC & side scatter \\
\hline ST & sterols \\
\hline StE & sterol esters \\
\hline $\mathbf{T}$ & Tisochrysis lutea standard strain \\
\hline $\begin{array}{l}\text { T + } \\
\text { TAG }\end{array}$ & T. lutea mutated strain \\
\hline TFA & al fatty acids \\
\hline
\end{tabular}

Keywords: Tisochrysis lutea, Nitrogen limitation, Growth phase, Flow cytometry, Fatty acids, Lipid classes 


\section{Introduction}

Microalgae are fast-growing organisms that produce a variety of compounds, such as polyunsaturated fatty acids (PUFA), sterols, pigments, antioxidants, and vitamins [1, 2]. Microalgal production has a large number of applications as feeds in aquaculture (reviewed in Hemaiswarya et al. [3]), biodiesel production (reviewed in Mata et al. [4]), human nutrition, cosmetic and therapeutic applications [5], stable isotope production [6], $\mathrm{CO}_{2}$ fixation from industrial flue gases [7], and waste water treatment for the removal of nutrients and contaminants [8]. The microalgal market generates a value of ca. U.S. $\$ 1.25 \times 10^{9}$ year $^{-1}$ with biomass production of 5,000 t dry matter per year [2]. Nowadays, one of the applications of microalgal lipids that receives much attention is biodiesel production [9] because of the high biomass and oil productivities of microalgae compared to oleaginous land plants [10]. Production cost of biofuels from microalgae, however, greatly excess fossil oil prices [11]. Production costs of microalgal biodiesel can be lowered substantially, by using a biorefinery approach [10] to produce fuel, power, and added-value chemicals on the one hand, and on the other, by improving microalgal productivities through genetic engineering [10] and optimizing culture conditions [12].

Microalgal culture is of great importance in aquaculture because there still is no viable alternative to replace living microalgae for feeding cultivated bivalve mollusks in the hatchery-nursery stage [13]. Lipid composition is considered as the most important factor of nutritional quality of bivalve diets, especially fatty acid (FA) composition and content [14]. In fact, long-chain omega-3 PUFA are among the most important nutrients that microalgae can provide. Essential fatty acids (EFA), particularly eicosapentaenoic acid (20:5n-3) and docosahexaenoic acid (22:6n-3) are important for bivalve survival and growth, particularly in larval stages [14-16], because of the limited capability for EFA de novo synthesis to meet nutritional requirements in bivalves [17]. Tisochrysis lutea (formely Isochrysis affinis galbana or T-Iso [18]) is a microalga widely used as live food in bivalve hatcheries because of its high content in 22:6n-3 and its relative ease of culture $[19,20]$. This strain tolerates relatively high culture temperatures [21], and its small size enables efficient ingestion and digestion by bivalve larvae [15, 22].

Factors such as temperature, light, and nutrient composition of culture medium generally affect growth and biochemical composition of the microalgae [23-26]. Nutrient deficiency in culture medium, such as nitrate starvation/reduction, can trigger reserve lipid accumulation, especially triacylglycerols (TAG), but concomitantly strongly limits growth [11, 27, 28]. Furthermore, microalgal biochemical 
composition, and specifically lipid content and profile, can change during culture aging [29, 30]. For example, protein accumulation is enhanced during T. lutea exponential phase; whereas, carbohydrates and lipids are mainly stored during the stationary phase [31]. Accordingly, harvesting at a specific growth phase and manipulating culture conditions, such as nutrient supply, may allow the orientation of lipid composition for specific purposes [32].

Bougaran et al. [33] performed a two-step mutation-selection procedure with T. lutea, based upon UVc irradiation followed by flow cytometry (FCM) selection to retain $10 \%$ of cells with the highest lipid content. A strain of $T$. lutea especially rich in lipids $(\mathbf{T}+)$ was obtained which accumulates twice the amount of neutral lipids (NL) under nitrogen (N)-reduced culture conditions compared to T. lutea standard strain, $\mathbf{T}$ [33]. A deep knowledge of the behavior of a particular microalgal strain in response to different culture conditions, such as nutrient supply, is essential for the optimization of microalgal production [34]. Some studies investigated the transcriptomic, proteomic, and biochemical changes observed in both strains under different $\mathrm{N}$-supplies in culture medium. Carrier et al. [35] compared transcriptome variations between the selected strain $\mathbf{T}+$ and the standard $\mathbf{T}$ grown under low-N supply and identified candidate genes involved in lipid over-accumulation in $\mathbf{T}+$. A proteomic study of both strains grown under nitrogen limitation revealed proteins potentially involved in carbon homeostasis, fatty acid synthesis, and carbohydrate catabolism [36]. Recently, Garnier et al. [37] investigated the proteomic and biochemical variations occurring in both strains grown in a chemostat under N-limitation, $\mathrm{N}$ repletion, and N-depletion. This study revealed that reserve lipid accumulation is favored by reorganization in carbon allocation in $\mathbf{T}+$. Furthermore, da Costa et al. [38] evaluated the effect of the high-lipid content of $\mathbf{T}+$ (grown under N-reduced medium and harvested at stationary phase) on the oyster Crassostrea gigas larval development and biochemical composition. The standard strain $\mathbf{T}$ grown under N-replete conditions and harvested at logarithmic phase was used as a control. The hypothesis was that diets rich in lipids may improve bivalve larval growth and competence as previously suggested in the literature (e.g. Powel et al. [39] or Haws et al. [40]). Too high triacylglycerols (TAG), saturated fatty acids (SFA), and monounsaturated fatty acids (MUFA) supplied by $\mathbf{T}+$ were responsible for poor survival and growth of larvae receiving these microalgae [38]. At present, little is known about the biochemical changes occurring in these two T. lutea strains under different $\mathrm{N}$ supplies in culture medium and at different growth phases in batch cultures. 
The objective of the present study was to determine the adequacy for different applications, such as aquaculture feeds or biodiesel production, of the biochemical composition of two T. lutea strains; a standard strain (T, CCAP 927/14) and a lipid rich mutated strain ( $\mathbf{T}+$, Bougaran et al. [33]) grown under two $\mathrm{N}$ supplies at two different growth phases.

To compare both strains, grown under N-replete and N-reduced conditions, an integrative approach was developed by measuring: (i) microalgal growth and associated, free-living bacterial community; (ii) several cellular variables (cell viability, morphology, intracellular lipid content, chlorophyll autofluorescence) by FCM ; (iii) total protein and carbohydrate contents and (iv) NL class, FA, and sterol compositions.

\section{Materials and methods}

\subsection{Microalgal culture}

Two Tisochrysis lutea strains, the standard strain (named here $\mathbf{T}$ ) and the T. lutea selected strain rich in lipids (named here $\mathbf{T}+$ ) were cultivated for 10 days. Both strains were obtained from the Culture Centre of Algae and Protozoa (strain CCAP 927/14) but T+ was obtained previously by a mutationselection procedure. The techniques used were detailed in Bougaran et al. [33], so only a brief overview will be given here. Batch cultures of the strain $\mathbf{T}$ grown under nitrate starvation and harvested in stationary phase were sorted by FCM. Nile Red was used to stain NL and this dye was added immediately before FCM sorting. The $10 \%$ of the cells showing the strongest fluorescence intensity per cell were selected and called S0. Three-subsamples of $12 \mathrm{~mL}$ of the S0 culture were disposed in sterile Petri dishes (100 mm). They were then exposed to UV irradiation for 32 min using a $\lambda=254 \mathrm{~nm}$ UV-C lamp (340 $\mu \mathrm{W} \mathrm{cm}{ }^{-2}$, Bioblock). After exposure, microalgal cells (S0M1, i.e. S0 population after mutation 1) were transferred to $100 \mathrm{~mL}$ Erlenmeyer filled with sterilized seawater enriched with Walne medium and maintained in the dark for $24 \mathrm{~h}$. After a 30-day period of growth recovery, the S0M1 population was sorted using Nile Red and FCM to select $10 \%$ of the cells showing the strongest fluorescence intensity. The resulting population S1M1 was further exposed to a second similar mutation step (32 min of irradiation with UV). Then, the resulting S1M2 population was sorted by FCM after recovery resulting in the S2M2 population. 
In our study, the effects of two nitrate concentrations in the enrichment of seawater $\left(1 \mathrm{~mL} \mathrm{~L}^{-1}\right)$ were investigated in both strains: (1) N-replete Conway medium (nitrate concentration of $1.2 \mathrm{mM}$ ) [41] and (2) N-reduced Conway medium (nitrate concentration of $0.6 \mathrm{mM}$, that is, half that of standard Conway medium [33]). Microalgae were grown in 6-L glass carboys (diameter $24 \mathrm{~cm}$ ) at $20-23^{\circ} \mathrm{C}$ under continuous illumination (180-220 $\mu \mathrm{mol}$ photons $\left.\mathrm{m}^{-2} \mathrm{~s}^{-1}\right)$ provided by cool-white fluorescent tubes. Seawater (salinity 34-35 PSU) was filtered to $1 \mu \mathrm{m}$, enriched with sterilized microalgal culture medium, and then autoclaved. A mixture of $3 \% \mathrm{CO}_{2}$-air was supplied to support growth and to maintain the $\mathrm{pH}$ within a range of 7.5-8.1. All cultures were performed in triplicates. Initial cell density was $1.025 \times 10^{6}$ cells $\mathrm{mL}^{-1}$.

\subsection{Cell density}

Cell density was assessed daily under a light microscope using Malassez slides. Specific growth rate was measured during exponential phase following the formula: $\mu=\ln (\mathrm{N} 2 / \mathrm{N} 1) / \mathrm{t} 2-\mathrm{t} 1$, with $\mu=$ cell growth in $\mathrm{d}^{-1}$, where $\mathrm{N} 1$ and $\mathrm{N} 2=$ cell density at time $1(\mathrm{t} 1)$ and time $2(\mathrm{t} 2)$ respectively [42].

Cell volume $\left(\mu \mathrm{m}^{3}\right.$ cell $\left.^{-1}\right)$ was assessed with an electronic particle counter Multisizer 3 equipped with a $100-\mu \mathrm{m}$ aperture tube.

\subsection{Flow cytometry}

Microalgae were evaluated by FCM using a three-color Guava EasyCyte Plus cytometer equipped with a laser emitting at $488 \mathrm{~nm}$ (Guava Technologies, Hayward, CA, USA). Analyses were realized with a flow rate of $0.59 \mu \mathrm{s} \mathrm{s}^{-1}$ for $30 \mathrm{~s}$. The same instrument settings were used for the duration of the experiment to allow comparison between days. Briefly, an aliquot of $200 \mu \mathrm{L}$ of microalgal culture diluted at 200,000 cells $\mathrm{mL}^{-1}$ was used to assess microalgal forward scatter (FSC), side scatter (SSC), chlorophyll autofluorescence, lipid content, viability, and bacterial concentration in the culture. FL3 fluorescence, corresponding to chlorophyll red autofluorescence at $670 \mathrm{~nm}$, was used as the discriminating factor to detect and select the microalgae within cytograms.

According to Veldhuis \& Kraay [43] chlorophyll autofluorescence was also used as a proxy of chlorophyll content to investigate relative chlorophyll variations during microalgal growth. The amount 
of chlorophyll that chloroplasts are able to accommodate is limited by cell size. Accordingly, to compare chlorophyll fluorescence in different conditions and strains, the autofluorescence of chlorophyll per cell should be expressed relative to cell volume [34]. Chlorophyll autofluorescence per cell volume was expressed as relative content in arbitrary units, using the following equation [34]:

Relative fluorescence $=$ autofluorescence of chlorophyll per cell $/$ cell volume

The lipophilic dye Bodipy 493/503 (4,4-difluoro-1,3,5,7,8-pentamethyl-4-bora-3a,4a-diaza-sindacene, Molecular probes, Invitrogen, Eugene, OR, USA) was used to assess intracellular lipid content of microalgae [44]. A $10 \mathrm{mM}$ stock solution of Bodipy 493/503 was made by diluting the commercial powder in DMSO. A $1 \mathrm{mM}$ working solution was then prepared by a 10 -fold dilution of the stock solution in distilled water. Samples were incubated with Bodipy at a final concentration of $10 \mu \mathrm{M}$ for 10 min at room temperature in darkness. Green fluorescence (GF) of Bodipy was expressed in GF of Bodipy per cell and in GF of Bodipy per cell volume.

Cell viability was assessed in chlorophyll-containing cells using a cell membrane-impermeable dye, SYTOX Green (Molecular probes, Invitrogen, Eugene, OR, USA) prepared at a final concentration of $0.2 \mu \mathrm{M}$. Samples were incubated for $10 \mathrm{~min}$ at room temperature in darkness. Cells were considered dead when they were permeable to SYTOX Green and emitted green fluorescence [45]. Dead cells were the red-fluorescent $T$. lutea cells that also exhibited green fluorescence. Results were expressed as percentage of dead cells [46].

Free-living bacteria in microalgae culture were stained by adding SYBR Green I (Molecular probes, Invitrogen, Eugene, OR, USA) at a final concentration of $1 \mu \mathrm{M}$, and incubating for $10 \mathrm{~min}$ at room temperature in darkness. Bacteria stained with SYBR green I were detected using FL1 as the discriminating factor and distinguished from microalgae according to FSC, SCC and chlorophyll-related red fluorescence levels, much greater in microalgae. Bacterial cell density was estimated from the flowrate measurement $\left(0.24 \mu \mathrm{s} \mathrm{s}^{-1}\right)$ of the flow cytometer [47], as all samples were run for $30 \mathrm{~s}$, and were expressed as number of cells $\mathrm{mL}^{-1}$. Results were also expressed as bacteria per T. lutea cell. 


\subsection{Biochemical analysis}

Samples of 250-300 x $10^{6}$ cells were collected at the late-logarithmic phase (L; after 4 days) and at stationary phase ( $\mathrm{S}$; after 10 days) for biochemical analyses ( $\mathrm{n}=3$ batches for each strain and culture medium). Samples for analysis of proximate biochemical composition (total protein and carbohydrate contents) were collected directly in graduated flasks, washed with 3.5\% ammonium formate to remove salts, centrifuged (3000 g, $10 \mathrm{~min})$, and the supernatant was removed. All samples were frozen and stored at $-20^{\circ} \mathrm{C}$. Samples for lipid analysis (FA, sterol and lipid class compositions) were collected on $450{ }^{\circ} \mathrm{C}$ pre-combusted GF/F glass-fiber filters (Whatman, diameter $47 \mathrm{~mm}$ ) and washed with $3.5 \%$ ammonium formate. Lipids were extracted in $6 \mathrm{ml}$ chloroform: methanol (2:1, v/v) according to Folch et al. [48], sealed under $\mathrm{N}_{2}$, and stored at $-20^{\circ} \mathrm{C}$.

Samples for proximate biochemical composition analysis were suspended in $2 \mathrm{ml}$ of distilled water and homogenized as described in da Costa et al. [38]. Then, aliquots for the different analyses were distributed into test tubes. Carbohydrates were analyzed following the method of Dubois et al. [49] using glucose as the standard. After sample hydrolysis in $1 \mathrm{~N} \mathrm{NaOH}$ at room temperature for $1 \mathrm{~h}$, total protein content was assayed using the Bio-Rad DC Protein Assay Kit (Bio-Rad Laboratories, Hercules, CA; USA) in microplates read at $750 \mathrm{~nm}$ with a Bio-Tek Synergy HT microplate reader (BioTek Instruments, Inc., Winooski, VT, USA) using BSA as a standard. Dry and ash-free weights were determined on a 300 $\mu \mathrm{L}$ aliquot of the first fraction $(2 \mathrm{~mL})$ distributed in pre-weighed capsules dried at $80^{\circ} \mathrm{C}$ for $48 \mathrm{~h}$ and subsequently combusted at $450^{\circ} \mathrm{C}$ for $5 \mathrm{~h}$.

Neutral lipid (NL) class composition was determined by HPTLC using $200 \times 100 \mathrm{~mm}$ silica-gel plates (Silicagel 60, Merck) according to Soudant et al. [50]. Silica plates were subjected to a first elution for eliminating impurities with a solution of hexane: diethylether $(1: 1, \mathrm{v} / \mathrm{v})$. The silica plates then were activated for $30 \mathrm{~min}$ at $120^{\circ} \mathrm{C}$. The samples were spotted on the plates with an automated sampler designed for TLC (Automatic TLC sampler 4 and software WinCATS, CAMAG, Muttenz, Switzerland). NL were separated by two successive developments, first with a solution of hexane: diethyl ether: acetic acid (20:5:0.5; v/v) and, after drying, with a solution of hexane: diethyl ether (97:3; v/v). Plates were dipped in a $3 \% \mathrm{CuSO}_{4}$ and $8 \% \mathrm{H}_{3} \mathrm{PO}_{4}$ solution and heated at $160{ }^{\circ} \mathrm{C}$ for $20 \mathrm{~min}$. The developed plates were analyzed with a Scanner-Densitometer, equipped with a monochromatic $370 \mathrm{~nm}$ bulb, and lipid classes were identified and quantified comparing band intensity between standards and samples using 
winCATS software. Standards employed for the identification and the quantification of compounds were sterols (ST), alcohols (AL), two different types of alkenones (ALK a and b), free fatty acids (FFA), triacylglycerols (TAG), glyceryl ethers (GE) and sterol esters (StE). All the lipid class standards and the chemicals used for HPTLC were purchased from Sigma-Aldrich, at the exception of alkenones, which were lab-made standards. Results were expressed as the quantity per cell (fg cell ${ }^{-1}$ ) and in weight percentage of total NL.

The NL and polar lipids (PL) of the microalgae were separated on a silica gel micro-column (30 mm x 5 mm; Kieselgel; Merck, Billerica, MA, USA, 70-230 $\mu \mathrm{m}$ mesh) heated to $450{ }^{\circ} \mathrm{C}$, deactivated with 6\% water as detailed in Soudant et al. [51] and analyzed following the method described by Marty et al. [52]. NL were eluted with $10 \mathrm{~mL}$ of chloroform: methanol $(98: 2, \mathrm{v} / \mathrm{v})$ and PL were eluted with $20 \mathrm{~mL}$ methanol. The PL fraction and half of the NL fraction were used for FA analysis; whereas, the other half of the NL fraction was preserved for sterol analysis. FA composition of PL and NL was determined as follows: after addition of the FFA 23:0 (2.3 $\mu \mathrm{g}$, Sigma) as an internal standard, samples were evaporated under $\mathrm{N}$ and transesterified with $1 \mathrm{ml}$ of $\mathrm{BF}_{3}-\mathrm{MeOH}$ (14\% by weight, Sigma) for 10 min at $95^{\circ} \mathrm{C}$ [53]. After cooling, $1 \mathrm{~mL}$ of hexane and $1 \mathrm{~mL}$ of distilled water were added to each sample vial, and vials were agitated and centrifuged (1000 g, $10 \mathrm{~min})$. The organic, upper phase containing fatty acid methyl esters (FAME) was collected and cleaned again with $1 \mathrm{~mL}$ of distilled water that was eliminated thereafter. FAME were recovered and analyzed by gas chromatography using a GC (HP 6890; HP, Wilmington, DE, USA) equipped with an auto-sampler, a capillary column (JW DB wax, $30 \mathrm{~m}$ length $\mathrm{x} 0.25 \mathrm{~mm}$ i.d. $\mathrm{x} 0.25$ $\mu \mathrm{m}$ film thickness), an on-column injector set at $60^{\circ} \mathrm{C}$ and a FID detector set at $300^{\circ} \mathrm{C}$. The carrier gas

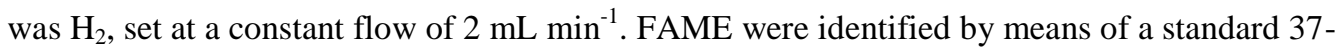
component FAME mix (Sigma) and other known standard mixtures from marine microalgae and bivalves [51]. FAME were quantified relative to the internal standard (23:0) and expressed as the quantity per cell $\left(f g\right.$ cell $\left.^{-1}\right)$ and in weight percentage for NL and PL.

Sterols from the other half of the NL fraction were hydrolyzed with sodium methoxide (MeONa $0.5 \mathrm{M}$ ) for $90 \mathrm{~min}$ at room temperature as described in Soudant et al. [54]. Sterols then were extracted in hexane as previously described for FAMEs and injected directly into a gas chromatograph Chrompak CP 9002 (Varian Inc., Walnut Creek, CA, USA) equipped with a Restek RTX65 fused silica capillary column (15 m x $0.25 \mathrm{~mm}, 0.25 \mu \mathrm{m}$ film thickness), an on-column injector set at $60{ }^{\circ} \mathrm{C}$, and a FID detector set at $280^{\circ} \mathrm{C}$. Hydrogen was used as the carrier gas at a constant pressure of 90 psi. The sterols were identified 
by comparisons of retention times with standards (Sigma), and cholestane (2.3 $\mu \mathrm{g}$; SUPELCO, Lyon, France) was used as an internal standard for sterol quantification. Sterols were expressed as quantity per cell (fg cell $\left.{ }^{-1}\right)$ and in weight percentage.

\subsection{Statistical analysis}

Data normality was first evaluated using the Shapiro-Wilk test. Homogeneity of variances was checked by means of the Barlett test. Two-way analysis of variance (ANOVA) with growth phase and N level in culture medium as factors was performed using STATISTICA software (Stat Soft, Inc., Tulka, OK, USA, version 12). When necessary, post hoc analyses with the LSD test were applied. Percentage data were transformed (arcsin square root of xi $100^{-1}$ ) to normalize variance [55]. Differences were considered statistically significant at $P \leq 0.05$. Correlations between morphological, physiological and biochemical variables were examined by Pearson's correlation coefficients using STATISTICA software.

FA data were analyzed statistically with a similarity percentage analysis (SIMPER) performed on the relative FA content to identify the differences of NL and PL composition between growth phase and culture medium for both $T$. lutea strains. FA composition in NL and PL of both T. lutea strains also were compared to identify strain-specific FA profiles. SIMPER identifies the FAs that mainly contribute to the variations between tested conditions. For example, to identify FA differences between strains, data from all tested conditions in each strain (growth phase, i.e. day 4 and day 10; and N supply, i.e. Nreduced and N-replete conditions) were pooled $(n=12)$. Similarly, for each strain we pooled data at each growth phase (i.e. N-reduced and N-replete conditions; $n=6$ ) to identify FA markers of growth phases. Only the FAs that cumulatively contributed up to $80 \%$ of the dissimilarities recorded were selected to identify the differences in the FA profile according to strain, culture condition, and growth phase [56]. Data on the relative FA percentages of the samples were logarithmically $(\log [\mathrm{x}+1])$ transformed and converted into a Bray-Curtis similarity matrix to start the multivariate analyses. The Bray-Curtis similarity matrix was used for a one-way analysis of similarities (ANOSIM) to test whether or not samples within NL or PL fractions clustered by strain, growth phase, and culture medium. ANOSIM calculates a global $\mathrm{R}$ statistic that weighs the differences between groups, with $\mathrm{R}=1, \mathrm{R}=0.5$ and $\mathrm{R}=0$ indicating a perfect, satisfactory, and poor separation of the clusters, respectively [49]. SIMPER and 
ANOSIM analysis of the relative FA percentages were performed using PRIMER (Quest Research Limited, Albany, Auckland, New Zealand, version 5).

\section{Results}

3.1. Microalgal growth

Microalgal growth and morphological characteristics of $\mathbf{T}$ and $\mathbf{T}+$ were monitored daily for 10 days (Fig.1). The selected strain $\mathbf{T}+$ reached a lower maximal cell density than $\mathrm{T}$ for both $\mathrm{N}$-replete and N-reduced conditions (Fig. 1A; ANOVA, $P<0.05$ ). Growth rates of $\mathbf{T}$ and $\mathbf{T}+$ were significantly affected by $\mathrm{N}$ supply, showing higher values for the N-replete condition (two-way ANOVA, $P<0.05$ ). The highest growth rate $\left(\mu_{\max }\right)$ was found in $\mathbf{T}$ grown under the N-replete condition $\left(1.2 \pm 0.1 \mathrm{~d}^{-1}\right)$. In both strains, stationary phase was reached on day 6 for the N-replete condition; whereas, microalgae grown under the N-reduced condition achieved stationary phase at day 5 (Fig. 1A).

Mean cell volume $\left(\mu \mathrm{m}^{3}\right)$ increased significantly from day 3 to day 10 (Fig. 1B; two-way ANOVA, $P<0.001$ ) and was significantly higher under N-reduced medium, for both strains (Fig. 1B; two-way ANOVA, $P<0.05)$. Mean cell volume of $\mathbf{T}+$ was significantly higher from day 4 in the $\mathrm{N}$ reduced supply and from day 5 for the N-replete supply, respectively. On day 10, mean cell volume was significantly higher in $\mathbf{T}+$ than in $\mathbf{T}$ regardless of $\mathrm{N}$ supply (69-75 vs 56-59 $\mu \mathrm{m}^{3}$ : Fig. 1B; one-way ANOVA, $P<0.05)$.

\subsection{Flow cytometry}

Forward scatter (FSC) decreased during the experiment in both strains and N supplies (data not shown). In $\mathbf{T}+$, the N-reduced condition resulted in lower FSC values beyond day 5, but not with $\mathbf{T}$. Side scatter (SSC) significantly decreased from day 1 to 2 and increased steadily thereafter, regardless of experimental conditions (data not shown). In both strains, SSC was significantly modified by growth phase and culture medium (two-way ANOVA, $P<0.001$ ). Both strains showed a similar pattern in SSC with an especially acute increase in $\mathbf{T}+(+68 \%$ vs $+54 \%$ in $\mathbf{T})$. 
The highest chlorophyll auto-fluorescence expressed per cell volume (a proxy of chlorophyll content per cell volume) was observed on day 2 under the N-reduced condition and on day 3 under the Nreplete medium (Fig. 1C). Thereafter, for both strains, the chlorophyll content proxy decreased steadily until the end of the trial, regardless of experimental conditions (Fig. 1C). The chlorophyll content proxy in $\mathbf{T}$ and $\mathbf{T}+$ was significantly higher under $\mathrm{N}$-replete medium (one-way ANOVA, $P<0.05$ ) than in other media.

A sharp increase in cell lipid content $(+422 \%$, as measured by Bodipy green fluorescence intensity per cell volume) occurred in $\mathbf{T}+$ in stationary phase for the N-replete supply, intensified under the N-reduced condition (+451\%, Fig. 1D). In T, cell lipid content per cell volume increased during stationary phase independently of N supply in culture medium (+424 and $+462 \%$ ) (one-way ANOVA, $P$ $>0.05)$.

In $\mathbf{T}$, the percentage of dead cells remained low for the duration of the experiment in both $\mathrm{N}$ conditions (<0.6\%; Table 1$)$. In $\mathbf{T}+$, the ratio of dead cells remained stable $(<1 \%)$ until day 10 : thereafter it increased significantly up to $14-15 \%$ in both $\mathrm{N}$ conditions (Table 1).

Bacterial cell density in $\mathbf{T}$ and $\mathbf{T}+$ slightly and steadily increased from day 1 to 9 , and sharply rose thereafter in both strains (Fig. 1E). For both strains, N-reduced conditions resulted in a significantly lower bacterial concentration (Fig. 1E; one-way ANOVA, $P<0.05$ ). T showed a lower bacteria / microalgae ratio than $\mathbf{T}+$ regardless to experimental conditions. In $\mathbf{T}$, independent of $\mathrm{N}$ supply in culture medium, the bacteria / microalgae ratio remained below 2 bacteria per microalgal cell during the duration of the trial, except on day 10 when it reached 2.4-2.7 bacteria per microalga (Fig. 1F). In $\mathbf{T}$, the bacteria / microalgae ratio was significantly affected by growth phase, with higher ratios at stationary phase (twoway ANOVA, $P<0.001)$. In $\mathbf{T}+$, the bacteria / microalgae ratio decreased from day 1 to day 4 . In contrast, this ratio increased thereafter from day 7 (Fig. 1F). $\mathbf{T}+$ showed a significantly lower bacteria / microalgae ratio at logarithmic phase than stationary phase (Fig. 1F; one-way ANOVA, $P<0.05$ ). In the stationary phase of $\mathbf{T}+$, the bacteria / microalgae ratio was significantly higher under N-replete than under N-reduced conditions (Fig. 1F; one-way ANOVA, $P<0.05$ ).

\subsection{Proximate biochemical composition}


Cell dry weight (DW) in $\mathbf{T}$ and $\mathbf{T}+$ was significantly higher for N-reduced supply and stationary phase (Fig. 2A; two-way ANOVA, $P<0.001$ ). In $\mathbf{T}$, a significantly lower ash content was found in Nreplete medium than in N-reduced medium (9-12\% and 15-17\% of DW, respectively; two-way ANOVA, $P=0.001$, data not shown); whereas, no effect of growth phase was identified (two-way ANOVA, $P=$ 0.742). In contrast, in $\mathbf{T}+$, no significant differences according to $\mathrm{N}$ supply and growth phase were found in ash content (15-18\% of DW; two-way ANOVA, $P>0.05$, data not shown).

Total protein content $\left(\mathrm{pg} \mathrm{cell}^{-1}\right.$ ) was significantly modified by growth phase in $\mathbf{T}$ and $\mathbf{T}+$, exhibiting higher values in logarithmic phase (Fig. 2B), with a tendency to decrease under N-reduced condition. In $\mathbf{T}+, \mathrm{N}$ supply and the interaction $\mathrm{N}$ supply/growth phase have significant effects on total protein content. The highest protein content was observed in logarithmic phase and N-replete medium (5.8 $\mathrm{pg} \mathrm{cell}^{-1}$; Fig. 2B); whereas, the lowest value was recorded in stationary phase and $\mathrm{N}$-replete medium (4.1 pg cell ${ }^{-1}$; Fig. 2B).

In $\mathbf{T}$, carbohydrate content was significantly higher in stationary than in logarithmic phase regardless to $\mathrm{N}$ supply and higher in the N-reduced condition than in the N-replete condition in logarithmic phase (Fig. 2C). In $\mathbf{T}+$, stationary phase and N-reduced supply resulted in an increase in carbohydrate content (two-way ANOVA, $P<0.001$ : Fig. 2C).

\subsection{Neutral lipid classes}

Neutral lipid cell content, as determined as the sum of NL classes, was significantly higher in stationary phase than logarithmic period in both strains ( $\mathbf{T}: 1,768-1,868$ vs $880-1,018 \mathrm{fg} \mathrm{cell}^{-1}$ and $\mathbf{T}+$ : 4,352-5,197 vs 766-1,669 fg cell $^{-1}$ : two-way ANOVA, $P<0.001$; Table 2). In $\mathbf{T}+$, total neutral lipid cell content was significantly higher in the N-reduced condition (two-way ANOVA, $P<0.001$; Table 2). Thus, in $\mathbf{T}+$, the highest total NL was recorded in stationary phase for the N-reduced supply $(5,197 \mathrm{fg}$ cell $^{-1}$; Table 2); whereas, the lowest value arose in logarithmic phase for the N-replete condition (766 fg cell $^{-1}$; Table 2). 
Sterol esters (StE) and hydrocarbons (HC) co-eluted. In $\mathbf{T}$, the $\mathrm{StE}+\mathrm{HC}$ proportions increased significantly during both phases for the $\mathrm{N}$ - reduced supply (Table 2); whereas, in $\mathbf{T}+$, such significant increase arose only in stationary phase for the N-reduced supply (Table 2).

The triacylglycerol (TAG) proportion in neutral lipids was about 3 to 4 times higher in $\mathbf{T}+$ than in $\mathbf{T}$ (Table 2). In both strains, the highest TAG proportion was recorded in stationary phase, regardless to $\mathrm{N}$-supply; whereas, the lowest value was observed in logarithmic phase for the N-replete condition. In $\mathbf{T}$, cell TAG content $\left(\mathrm{pg} \mathrm{cell}^{-1}\right)$ increased significantly from logarithmic $\left(166-240 \mathrm{fg}\right.$ cell $\left.^{-1}\right)$ to stationary phase (539-566 $\mathrm{fg} \mathrm{cell}^{-1}$ ) but did not vary according to $\mathrm{N}$ supply (Fig. 3A). In $\mathbf{T}+$, TAG contents increased sharply from 619 and 1,515 $\mathrm{fg} \mathrm{cell}^{-1}$ in logarithmic phase to 4,099 and 4,958 $\mathrm{fg} \mathrm{cell}^{-1}$ in stationary phase under $\mathrm{N}$ replete and $\mathrm{N}$-reduced conditions, respectively (Fig. 3A).

FFA proportions in $\mathbf{T}$ and $\mathbf{T}+$ were significantly lower in stationary phase (3-10\% in logarithmic phase $v s$ 1-6\% in stationary phase; Table 2). Alcohols (AL) were detected only in stationary phase, and in low proportions $(<0.5 \%$; Table 2$)$.

Proportions of alkenones (sum of the bands ALK a and ALK b) were much higher in $\mathbf{T}$ (6068\%) than in $\mathbf{T}+(1-3 \%$ ) (Table 2). In $\mathbf{T}$, alkenone content increased during growth by about $40 \%$ (from 602-653 to 1058-1136 fg cell $^{-1}$; Fig. 3B) under N-replete and N-reduced conditions. In $\mathbf{T}$, mean total alkenones was slightly but significantly higher for the N-reduced condition in stationary phase (Fig. 3B). In $\mathbf{T}+$, growth phase and $\mathrm{N}$ supply had significant effects on total alkenone content, with the lowest value $\left(20 \mathrm{fg} \mathrm{cell}^{-1}\right)$ recorded in logarithmic phase with N-replete supply and the highest value $\left(35 \mathrm{fg} \mathrm{cell}^{-1}\right)$ in stationary phase in the N-reduced condition (Fig. 3B).

Relative and absolute sterol (ST) contents were globally lower in T (3-4\% of total NL; 29-63 fg cell $^{-1}$; Table 2 and Fig. 3C) than in $\mathbf{T}+\left(2-7 \%\right.$ of total NL; 54-116 fg cell ${ }^{-1}$; Table 2 and Fig. 3C). Results of two-way ANOVA showed the significant effects of growth phase and nutrient supply in $\mathbf{T}+$ total sterol. The highest ST proportion in $\mathbf{T}+$ was recorded in logarithmic phase for the N-replete supply (7\%); whereas, the lowest proportion was observed in stationary phase regardless of $\mathrm{N}$ supply (2-3\%; Table 2). In contrast, in $\mathbf{T}$, ST proportion remained constant regardless to experimental conditions. Sterol cell 
content (fg.cell ${ }^{-1}$ ) in both strains was higher in stationary phase, independent of $\mathrm{N}$ supply. Brassicasterol (determined with GC-FID) was the sole sterol present in both strains (data not shown).

\subsection{Fatty acids}

\subsubsection{Fatty acids in neutral lipids}

In $\mathbf{T}$, TFA content in NL was significantly lower in logarithmic phase (303-317 $\left.\mathrm{fg} \mathrm{cell}^{-1}\right)$ than in stationary phase (569-606 fg cell ${ }^{-1}$ ) regardless to $\mathrm{N}$ supply (Supplementary Table 1). The main FAs in NL were $18: 1 \mathrm{n}-9$ (19.5-25.5\%), 14:0 (7.9-13.1\%), 16:0 (10.0-13.4\%), 18:4n-3 (9.4-15.4\%) and 22:6n-3 (13.217.0\%) (Supplementary Table 1).

In $\mathbf{T}+$, TFA content of NL varied significantly according to growth phase and N supply (twoway ANOVA, $P<0.001)$, showing the highest concentration in stationary phase and $\mathrm{N}$-reduced conditions (Supplementary Table 2). The main FAs in NL were 14:0 and 18:1n-9, which were present in high proportions (between 28 and 33\% of TFA in NL) in all experimental conditions (Supplementary Table 2).

In NL, T and T+ FA profiles differed for 14:0, 18:0, 20:0, 22:0, 16:1n-7, 18:1n-9, 16:3n-6, 18:2n-6, 18:4n-3, 18:5n-3, 21:5n-3, 22:5n-6 and 22:6n-3 (Fig. 4A; 20.7\% dissimilarity, SIMPER) resulting in higher proportions of saturated and mono-unsaturated fatty acids and lower polyunsaturated fatty acids in $\mathbf{T}+$ than in $\mathbf{T}$. A significant effect of strain on FA composition in NL was recorded (Global R: 1 , Stress $=0.001$, ANOSIM).

In $\mathbf{T}$ NL, the main changes of FA profile attributable to growth phase were associated with 14:0, $16: 0,18: 0,20: 0,22: 0,16: 1 n-7,18: 1 n-7,18: 2 n-6,18: 3 n-3,18: 4 n-3,18: 5 n-3,21: 5 n-3,22: 5 n-6$, and 22:6n3 (Fig. 5B; 9.2\% dissimilarity, SIMPER), and the overall difference was statistically significant (Global R: 0.996, Stress $=0.002$, ANOSIM). Proportions of 16:0, 18:1n-9, and 18:2n-6 decreased in stationary phase while 16:1n-7, 18:4n-3 and 22:6n-3 concomitantly increased (Supplementary Table 1). In T+ NL, the main changes of FA profile related to growth phase concerned 14:0, 18:0, 22:0, 16:1n-9, 16:1n-7, 18:1n-7, 18:3n-3, 18:4n-3, 22:5n-6, and 22:6n-3 (Fig. 4B; 8.8\% dissimilarity, SIMPER), and the overall difference was statistically significant (Global R: 1 , Stress $=0.002$, ANOSIM). In T+, in stationary phase, 14:0, 16:1n-7, 18:3n-3, and 18:4n-3 increases were counterbalanced by 18:0, 18:1n-9, 18:1n-7, and 22:6n-3 decreases (Supplementary Table 2). 
In $\mathbf{T}$ NL, the main FA differences related to N supply concerned 14:0, 16:0, 18:0, 20:0, 22:0, $16: 1 n-7,18: 1 n-7,18: 1 n-9,18: 2 n-6,18: 3 n-3,18: 4 n-3,18: 5 n-3,21: 5 n-3$, and 22:6n-3 (7.4\% dissimilarity, SIMPER); whereas, in T+, such differences were associated with 14:0, 18:0, 22:0, 16:1n-7, 16:1n-9, 18:1n-7, 18:2n-6, 18:3n-3, 18:4n-3, 22:5n-6, and 22:6n-3 (6.4\% dissimilarity, SIMPER). No significant effects of N level were recorded in T (Global R: 0.243, Stress $=0.082$, ANOSIM) or T+ (Global R: 0.052, Stress $=0.195$, ANOSIM)

\subsubsection{Fatty acids in polar lipids}

In T, cell TFA content in PL decreased with N-reduced supply and stationary phase (two-way ANOVA, $P<0.001$ ), resulting in values in N-L $>\mathrm{N}-\mathrm{S}=\mathrm{N} 1 / 2-\mathrm{L}>\mathrm{N} 1 / 2-\mathrm{S}$ (Supplementary Table 3 ). In contrast, in $\mathbf{T}+$, there were no significant effects of $\mathrm{N}$ supply or growth phase on cell TFA content in PL (Supplementary Table 4). The main FA present in PL of $\mathbf{T}$ and $\mathbf{T}+$ were 14:0, 16:0, 18:1n-9, 18:4n-3, and 22:6n-3 (Supplementary Tables 3 and 4). T and T+ FA profiles differed for 14:0, 16:0, 16:1n-7, 18:1n-9, 16:2n-4, 18:2n-6, 18:3n-3, 18:4n-3, 18:5n-3, 21:5n-3, 22:5n-3, and 22:6n-3 (Fig. 5A; 8.2\% dissimilarity, SIMPER). A significant effect of strain on FA composition in PL was recorded (Global R: 0.803, Stress $=0.001$, ANOSIM)

In $\mathbf{T}$, the main FA differences in PL related to growth phase were in 14:0, 18:1n-7, 18:2n-6, 18:3n-6, 18:3n-3, 18:5n-3, 20:5n-3, 21:5n-3, 22:5n-6, 22:5n-3, and 22:6n-3 (Fig. 5B; 6.7\% dissimilarity, SIMPER); whereas, in $\mathbf{T}+$, differences were in 16:0, 16:1n-9, 18:1n-9, 18:1n-7, 16:2n-4, 18:3n-6, 18:4n3, 18:5n-3, 20:4n-6, 20:5n-3, and 22:5n-3 (Fig. 5B; 5.6\% dissimilarity, SIMPER). These FA composition differences were significant in T (Global R: 0.835, Stress $=0.002$, ANOSIM) and T+ (Global R: 0.757, Stress $=0.002$, ANOSIM). In T PL, in stationary phase, the percentages of 14:0, 18:2n-6, 18:3n-3, and 18:5n-3 decreased; whereas, 22:6n-3 increased (Supplementary Table 3). In T+ PL, the percentage of 18:1n-9 increased while 18:4n-3 and 18:5n-3 decreased (two-way ANOVA, $P<0.001$; Supplementary Table 4).

In T PL, the main FA differences relative to N supply were in 14:0, 16:1n-7, 18:1n7, 18:2n-6, 18:3n-3, 18:3n-6, 18:5n-3, 21:5n-3, 22:5n-3, 22:5n-6, and 22:6n-3 (6.2\% dissimilarity, SIMPER); 
whereas, in $\mathbf{T}+$ differences were in 14:0, 16:0, 16:1n-9, 18:1n-7, 18:1n-9, 18:3n-3, 18:3n-6, 18:4n-3, 18:5n-3, 20:5n-3, and 22:5n-3 (4.9\% dissimilarity, SIMPER). These FA profile differences were significant in $\mathbf{T}$ (Global R: 0.32, Stress $=0.045$, ANOSIM), but not in $\mathbf{T}+($ Global R: 0.176, Stress $=$ 0.12 , ANOSIM).

In $\mathbf{T}$ PL, for N-reduced supply, the percentages of 14:0, 18:2n-6, 18:3n-3, and 18:5n-3 decreased; whereas, 22:5n-6 and 22:6n-3 increased. In $\mathbf{T}+\mathrm{PL}$, for N-reduced supply, the percentages of 14:0, 16:0, and 18:1n-9 significantly increased, counterbalanced by $18: 3 n-3$ and $18: 4 n-3$ decreases.

3.6. Relationships between morphological, physiological and biochemical variables

Cell volume $\left(\mu \mathrm{m}^{3}\right)$ was positively related to $\mathrm{SSC}\left(\right.$ Cell volume $=0.638 * \mathrm{SSC}+12.998 ; \mathrm{R}^{2}=$ 0.605; $P<0.001$ ). Total free sterols (expressed in $\mathrm{fg} \mathrm{cell}^{-1}$ and determined by HPTLC) were well correlated to cell volume $\left(\mu \mathrm{m}^{3}\right)\left(\right.$ Total free sterols $=2.712 *$ Cell volume $\left.-86.107 ; \mathrm{R}^{2}=0.867 ; P<0.001\right)$. A significant linear correlation of Bodipy fluorescence intensity per cell with total TAG+ALK (fg cell ${ }^{-1}$ ) was also found $\left(\mathrm{TAG}+\mathrm{ALK}=9.1522 *\right.$ Bodipy $\left.+264.6855 ; \mathrm{R}^{2}=0.991 ; P<0.001\right)$.

\subsection{Productivity}

The highest dry weigh productivity $\left(\mathrm{mg} \mathrm{L}^{-1} \mathrm{day}^{-1}\right)$ was observed in $\mathbf{T}$ under N-replete conditions in logarithmic phase (Table 3). Protein productivity was enhanced in $\mathbf{T}+$ under N-replete supply in logarithmic phase (Table 3). Carbohydrate productivity was maximized under N-reduced conditions in both strains in logarithmic phase (51-54 $\mathrm{mg} \mathrm{L}^{-1}$ day $^{-1}$; Table 3). The highest total lipid productivity was observed in logarithmic phase in $\mathbf{T}+$ under N-reduced condition (Table 3). In the strain $\mathbf{T}+, \mathrm{NL}$ productivity was enhanced maximized under $\mathrm{N}$-reduced condition in stationary phase $\left(11 \mathrm{mg} \mathrm{L}^{-1}\right.$ day $^{-1}$; Table 3). NL and TAG productivity were also high under N-reduced condition in logarithmic phase and N-replete supply in stationary phase (8-9 $\mathrm{mg} \mathrm{L}^{-1} \mathrm{day}^{-1}$; Table 3$)$. In $\mathbf{T}$, alkenone productivity was enhanced in logarithmic phase regardless of $\mathrm{N}$ supply in culture medium (Table 3). The highest DHA productivity was observed in both strains with N-replete supply in logarithmic phase $\left(1 \mathrm{mg} \mathrm{L}^{-1}\right.$ day $^{-1}$; Table 3). 


\section{Discussion}

Lower maximal cell density was recorded in $\mathbf{T}+$ compared to $\mathbf{T}$ regardless to $\mathrm{N}$ supply. Lower maximal cell density in the mutated $T$. lutea strain $(\mathbf{T}+)$ has been reported previously in $\mathrm{N}$-reduced conditions [35, 36]. This difference can be explained by the intrinsic biochemical characteristics of both strains, as $\mathbf{T}+$ is a lipid-rich selected strain [33] which exhibited higher total lipid content and particularly TAG content. Lower cell growth occurred in the N-reduced condition as cell lipid content increased, which is consistent with previous studies [28, 57].

A decrease in cell volume during the first days of culture (days 3-4) was observed for all experimental conditions. This probably was caused by the intensive division of cells. FSC and SSC signals measured by flow cytometry drastically changed with culture age. FSC steadily decreased while SSC increased from day 2 to 10. In our study, SSC values and cell volume were related with a linear regression. Increases in SSC values in N-reduced medium and stationary phase may also be partially explained by an increase in cell complexity related to lipid accumulation in lipid droplets during stationary phase as previously reported in Pseudo-nitzschia multiseries [46].

Chlorophyll content relative to cell volume was lower in the N-reduced condition. Chlorophyll $a$ and protein synthesis rely on $\mathrm{N}$ uptake [58] and, accordingly, $\mathrm{N}$ availability in culture medium, as observed in our study. Moreover, as cultures aged during stationary phase, chlorophyll content steadily decreased. This chlorophyll $a$ decrease was related to a lower availability of $\mathrm{N}$ for protein synthesis in the closely-related species I. galbana at low nitrate supply [59]. We observed a decrease in protein quantity $\left(\mathrm{pg}\right.$ cell $\left.^{-1}\right)$ in stationary phase and the N-reduced condition in $\mathbf{T}$, but not in $\mathbf{T}+$. Reduced content of proteins also was reported in I. galbana grown to stationary phase [60] and in T. lutea grown in Nreduced medium [25].

Bacterial cell density increased slightly from day 1 to 7 or 9 in $\mathbf{T}+$ and $\mathbf{T}$, respectively. Thereafter, bacterial load rose, reaching maximal levels on day 10 regardless to experimental conditions. This may reflect increasing exudate production in aging cultures [61] exudates are known to be bacterial substrates [62]. Thus, the higher cell density of bacteria recorded in $\mathbf{T}+$ may result from higher amounts of exudates. As the concentration of $\mathbf{T}+$ dead cells increased on day 10 in both $\mathrm{N}$ conditions, however, the 
sharp increase in bacterial load at the end of $\mathbf{T}+$ culture growth may also result from an increase in organic matter released by dead cells. Bacteria present in Pseudo-nitzschia multiseries xenic cultures was previously reported to take advantage of released organic materials from dead microalgal cells [46]. In both strains, bacterial cell density was higher when microalgae were grown in the N-replete condition. As the bacteria/T. lutea ratio (data not presented) was similar in both $\mathrm{N}$ conditions, substrate on which bacteria were growing seemed to rely on microalgal cell density (and thus on exudate production). It should be noted that bacteria measured with FCM are free-living bacteria present in the culture; however, some bacteria can also be attached to microalgal cells [46]. Attached bacteria were not taken into account because their flow-cytometric signals are not distinguishable within those of $T$. lutea. The contribution of attached bacteria to total bacteria was assumed to be low, as previous studies reported that attached bacteria are present in low quantities in diatoms [63].

Although fluorescent dyes, such as Bodipy and Nile Red, offer a faster, easier, and cheaper way to measure lipids than gravimetric and chromatographic methods, the qualitative and quantitative variability in the way these compounds stain various microalgae species must be controlled [64]. Bodipy is a highly lipophilic, neutral fluorochrome that selectively stains lipids including FA, TAG, alkenones, cholesteryl esters, cholesterol, phospholipids, and ceramides [65]. Bodipy has been used recently as a potential alternative to the classic dye Nile Red [61] because it is insensitive to polarity [66] and allows visualization of lipid droplets [67]. In our study, we combined lipid content data (fg cell ${ }^{-1}$ ) of standard and mutant $T$. lutea to address the accuracy of Bodipy staining for rapid screening of lipid content in this species. Bodipy per cell was correlated positively with TAG+ALK content (fg cell $\left.{ }^{-1}\right)$. Thus, our results showed that Bodipy is a good tool for a rapid screening of reserve lipids in T. lutea.

The oleaginous strain $\mathbf{T}+$ accumulated TAG especially in the $\mathrm{N}$-reduced condition and stationary phase. T-Iso and I. galbana were previously reported to accumulate lipid as TAG in N-reduced conditions $[12,68]$ and stationary phase [60]. In the present study, T. lutea (standard strain $\mathbf{T}$ ) slightly increased TAG content during stationary phase, with no effects of N supply. Instead, in this strain, NL appeared to be accumulated in the form of alkenones in $\mathrm{N}$-reduced medium and stationary phase. The main alkenones were C37 and C38 long-chain unsaturated methyl and ethyl ketones (data not shown); total alkenones accounted for 60 to $68 \%$ of total NL. Several studies indicate that alkenones per cell increase with decreasing growth and $\mathrm{N}$-reduced culture $[32,69,70]$. Alkenone biosynthesis pathways and cellular machinery implied in their production remains unknown [71]. Versteegh et al. [72] speculated 
that alkenones may play a role in the photosynthetic pathway.More recently, however, Eltgroth et al. [71] suggested that alkenones may be synthesized in chloroplasts and then exported to cytoplasmic lipid bodies for storage and eventual metabolism. The storage function of alkenones is supported by the high quantity of alkenones (about 75\%) in lipid bodies of T. lutea [73] leading these authors to rename these lipid bodies as "alkenone bodies". These authors hypothesized that alkenones are synthetized in the internal space of endoplasmic reticulum membranes through the support of the protein V-ATPase on the outer membrane of endoplasmic reticulum, and then alkenones are transferred to alkenone bodies [73]. Garnier et al. [37] identified in the T. lutea proteome a very-long-chain 3-oxoacyl-CoA reductase (Kcr) that is potentially involved in alkenone synthesis. Production of alkenones seemed to be specific to some prymnesiophyte taxa (as Isochrysis or Emiliania). These organisms produce only small amounts of TAG [74], but instead produce alkenones [24, 75]. Our results agree with a "metabolic dichotomy" between TAG and alkenones in the two tested strains. Furthermore, alkenone production appeared to be strainspecific within the Isochrysis Genus [75]. The same authors stated that only the strains containing brassicasterol or epibrassicasterol contained long-chain alkenones. But, in our study, both T. lutea strains contained brassicasterol (data not shown).

Overall, we conclude that TAGs are the main lipids stored in the oleaginous strain $\mathbf{T}+$; whereas, alkenones may play an energy storage role in the standard strain $\mathbf{T}$. Concomitantly, in both strains, carbohydrates were enhanced in stationary phase, as previously reported in T-Iso by Brown et al. [31]. In stationary phase, the greatest carbohydrate increase was measured in the N-reduced condition, as well as the highest TAG or alkenone contents in $\mathbf{T}+$ and $\mathbf{T}$, respectively. In the oleaginous strain Pseudochlorococcum sp., carbohydrate accumulation prior to, and simultaneously with TAG accumulation has been reported [76], suggesting that carbohydrates are used as primary energy storage and TAG as secondary storage. Carbohydrates might be converted into TAGs when $\mathrm{N}$ starvation strengthens. There is no literature, however, establishing/mentioning such a relationship between alkenones and carbohydrates.

In $\mathbf{T}$ and $\mathbf{T +}$, total free sterols increased in stationary phase, as previously reported in $T$. lutea [77] and I. galbana $[32,77]$ under N limitation. Total free sterol (fg cell $\left.{ }^{-1}\right)$ was well correlated to cell volume, likely reflecting membrane expansion as cell size increased. In contrast, TFA in PL (part of the membrane lipids as total sterols) were quite stable regardless of culture age and $\mathrm{N}$ supply in both strains. Taking into account the increases in cell volume observed for both strains in the N-reduced condition and 
stationary phase, we hypothesize that plasma membrane increased with cell volume (as revealed above in the link with total sterols) while concomitantly chloroplast-related thylakoid membrane lipids decreased (assuming chlorophyll $a$ as a good proxy of cell chloroplast content). Sterol contents in thylakoid membranes are low compared to sterol contents present in plasma membranes [78, 79]. As mentioned above, the higher free sterol content in $\mathbf{T}+$ also can be related to cell volume differences between both strains.

FA profiles differed between $\mathbf{T}+$ and $\mathbf{T}$ in both NL and PL irrespective of N supply and growth phase. $\mathbf{T}+$ contained more saturated (SFA) and monounsaturated (MUFA) (especially 14:0 and 18:1n-9), but less polyunsaturated fatty acids (18:4n-3, 18:5n-3, 22:5n-6, and 22:6n-3) in NL, and to a lesser extent, in PL. This suggests that induced mutation of $\mathbf{T}+$ resulted in deep changes in FA and alkenone biosynthesis pathways and/or their respective activity intensities. Lower PUFA synthesis in $\mathbf{T}+$ may partially explain the lower growth of $\mathbf{T}+$ by impairing the ability to synthesize new membranes in the division process.

Beyond their "intrinsic" difference in FA profiles, $\mathbf{T}+$ and $\mathbf{T}$ responded differently in FA compositions in membrane lipids when reaching stationary phase. In T, 14:0, 18:2n-6, and 18:3n-3 decreased while 22:6n-3 increased; whereas, in $\mathbf{T}+, 18: 4 n-3$ decreased while 18:1n-9 increased. Such a trend has been reported in I. galbana TFA relative contents at late stationary phase, with a 18:4n-3 decrease concomitant with 16:0 and 18:1n-9 increases [60]. In contrast, 18:5n-3 decreased in both strains. As thylakoid lipids in T-Iso contain high-levels of 18:3n-3, 18:4n-3, and 18:5n-3 [80], a 18 PUFA decrease, in PL, in both strains, can be associated with a thylakoid membrane relative content reduction at stationary phase. This is in agreement with the observed decrease in chlorophyll content in both strains when cultures aged.

Upon N starvation, changes in FA profiles in both NL and PL were more limited than those observed as cultures aged and often inconsistent between both strains. Total PUFA increased in PL in T (not always in significant manner) while it decreased in $\mathbf{T}+$. In $\mathbf{T}$, this increase was mostly associated with 22:5n-6 and 22:6n-3, compensated by a 14:0 decrease. In $\mathbf{T}+$, lower PUFA was mostly associated with 18:3n-3, 18:4n-3, and 22:5n-3 decreases and concomitant 14:0, 16:0, and 18:1n-9 increases. The response of $\mathbf{T}+$ to $\mathrm{N}$ reduction agrees with several studies showing that levels of PUFA decreased in $\mathrm{N}$ - 
reduced conditions, with SFA and/or MUFA relative contents simultaneously increasing [30, 60, 81, 82]. Increases in SFA and/or MUFAs, in total lipids, in N-reduced supply, are consistent with other studies in I. galbana $[12,83,84]$. A $18: 4 n-3$ decrease concomitant to $16: 0$ and $18: 1 n-9$ percentages increases in TFA also has been reported in I. galbana with low N availability [24].

The oleaginous strain $\mathbf{T}+$ stored high quantities of TAG and thus of TFA (mainly SFA and MUFA), in stationary phase and the N-limiting condition, suggesting that $\mathbf{T}+$ could also be a good candidate for biofuel production. Similarly, N limitation and stationary phase increased alkenone content in T. O'Neil et al. [85] reported a method to produce a "jet fuel" range of hydrocarbons from alkenones by butenolysis. Thus, biorefinery processing of $\mathbf{T}$ and $\mathbf{T}+$ oil for both biofuel (TAG and/or alkenones) and DHA production can be considered as potential biotechnological applications of these strains. Health benefits of 22:6n-3 (DHA) include the prevention and treatment of chronic diseases such as coronary heart disease, hypertension, type II diabetes, ocular diseases, arthritis and cystic fibrosis [86]. T. lutea is one of the most widely cultivated species because it is a good source of 22:6n-3. In T, 22:6n-3 increased in stationary phase, in both PL and NL; whereas, it remained constant in $\mathbf{T}+$. Increase in 22:6n-3 proportion, in total lipids and stationary phase, has been previously reported in I. galbana [60, 82]. Moreover, Tonon et al. [87] reported that 20:5n-3 and 22:6n-3 levels increased in total FA extracts and TAG FA extracts upon the transition to the stationary phase in Pavlova lutheri. In N-reduced conditions, proportion of 22:6n-3, especially in PL, was enhanced in the standard strain $\mathbf{T}$ in both exponential and stationary phases; whereas, in the oleaginous strain $\mathbf{T}+$, the proportion of 22:6n-3 in NL decreased for $\mathrm{N}$ reduced supply. Some authors reported that 22:6n-3 relative abundance decreased in $\mathrm{N}$ limited conditions in I. galbana [12, 24, 88]. In contrast, other authors showed that $\mathrm{N}$ reduction did not affect 22:6n-3 levels in I. galbana [84] and I. aff. galbana [83]. We found a similar productivity of 22:6n-3 in TL (1.0-1.1 mg $\mathrm{L}^{-1}$ day $^{-1}$ ) in $\mathbf{T}$ and $\mathbf{T}+$ grown in N-replete conditions, in logarithmic phase.

Biorefining aims for a complete valuation of the biomass source, such as microalgae, to produce fuel, power, and added-value chemicals that can be used in industry [89]. T. lutea is a valuable source of PUFA, proteins, carbohydrates, chlorophyll $a$ and fucoxanthin [90], and thus it is a good candidate for biorefineries. Recently, a green, downstream-processing platform to extract bioactive compounds from $I$. galbana using generally recognized as safe (GRAS)-solvents and pressurized technologies was developed 
[89]. Future studies should investigate biorefining of the standard and selected T. lutea strains to completely evaluate value of the biomass, i.e. TAG, alkenones, PUFA, fucoxanthin, etc.

\section{Conclusions}

This work provides an in-depth physiological and biochemical analysis of the effect of $\mathrm{N}$ enrichment and growth phase on a standard and a selected $T$. lutea strain grown in batch culture. Measurements using FCM and analytical chemistry provided a complete description of the physiological status of two T. lutea strains under two $\mathrm{N}$ supplies in culture medium during 10 days. For instance,

Bodipy fluorescence intensity per cell showed a good correlation with TAG+ALK (fg cell $\left.{ }^{-1}\right)$. This showed the potential of Bodipy to perform rapid screening of reserve or total lipid contents in T. lutea. Our results show a "metabolic dichotomy" between TAG accumulation in the mutated strain $\mathbf{T}+$ and alkenone accumulation in the standard strain $\mathbf{T}$. Each strain had a characteristic FA profile in NL and PL. $\mathbf{T}+$ is characterized by a higher content of SFA and MUFA (mainly 14:0 and 18:1n-9); whereas, T contained more PUFA (18:4n-3, 18:5n-3 and 22:6n-3).

Growth phase induced more changes in FA profiles in NL and PL than N level in culture medium in both strains. Stationary phase and N-reduced medium increased TFA and sterol contents in both strains. Stationary phase also increased 22:6n-3 content in both PL and NL in $\mathbf{T}$. The lipid data in this study provides a comprehensive lipid profile for both strains at different growth phases and $\mathrm{N}$ supplies, which may be useful for comparative studies and a better understanding of lipid synthesis in $T$. lutea strains.

\section{Author's contribution}

F.D.C., R.R. and P.S. designed the research. G.B. and J.P.C. provided the mutated T. lutea strain $\mathbf{T}+$. F.D.C. performed the microalgal cultures. F.D.C., C.Q. and F.L.G. performed the biochemical analysis. F.D.C. and P.S. wrote the paper and analyzed the data. P.S. and R.R. supervised the work. All authors approved the final version of the manuscript. 


\section{Conflict of interest statement}

Authors declare that the research was conducted in the absence of any commercial or financial relationships that could be construed as a potential conflict of interest.

\section{Acknowledgements}

F. da Costa was funded through a postdoctoral fellowship from the Fundación Juana de Vega (Spain) and hosted at IFREMER. We would like to acknowledge the invaluable aid of Nelly Le Goïc and Christophe Lambert with flow cytometry study. Great thank to Dominique Ratiskol for her help in microalgae cultivation. We would like to thank Carmen González-Fernández from LEMAR for her advice in SIMPER and ANOSIM analysis. A great thanks to G. Wikfors from Milford laboratory for improving the English of this manuscript.

\section{References}

[1] M. Koller, A. Muhr, G. Braunegg, Microalgae as versatile cellular factories for valued products, Algal Res. 6 (2014) 52-63, http://dx.doi.org/10.1016/j.algal.2014.09.002.

[2] O. Pulz, W. Gross, Valuable products from biotechnology of microalgae, Appl. Microbiol. Biotechnol. 65 (2004) 635-648, doi:10.1007/s00253-004-1647-x.

[3] S. Hemaiswarya, R. Raja, R.R. Kumar, V. Ganesan, C. Anbazhagan, Microalgae: a sustainable feed source for aquaculture, World J. Microbiol. Biotechnol. 27 (2011) 1737-1746, doi:10.1007/s11274-0100632-z.

[4] T.M. Mata, A.A. Martins, N.S. Caetano, Microalgae for biodiesel production and other applications: a review, Renew. Sust. Energ. Rev. 14 (2010) 217-232, http://dx.doi.org/10.1016/j.rser.2009.07.020.

[5] R. Raja, S. Hemaiswarya, N.A. Kumar, S. Sridhar, R. Rengasamy, A perspective on the biotechnological potential of microalgae, Crit. Rev. Microbio. 34 (2008) 77-88, http://dx.doi.org/10.1080/10408410802086783.

[6] F.G. Acién Fernández, J.M. Fernández Sevilla, T.A. Egorova-Zachernyuk, E. Molina Grima, Costeffective production of ${ }^{13} \mathrm{C},{ }^{15} \mathrm{~N}$ stable isotope-labelled biomass from phototrophic microalgae for various 
biotechnological applications, Biomol. Eng. 22 (2005) 193-200,

http://dx.doi.org/10.1016/j.bioeng.2005.09.002.

[7] B. Wang, Y. Li, N. Wu, C.Q. Lan, $\mathrm{CO}_{2}$ bio-mitigation using microalgae, Appl. Microbiol. Biotechnol. 79 (2008) 707-718, doi:10.1007/s00253-008-1518-y.

[8] L. Wang, M. Min, Y. Li, P. Chen, Y. Chen, Y. Liu, Y. Wang, R. Ruan, Cultivation of green algae Chlorella sp. in different wastewaters from municipal wastewater treatment plant, Appl. Biochem. Biotechnol. 162 (2010) 1174-1186, doi:10.1007/s12010-009-8866-7.

[9] Y. Chisti, Biodiesel from microalgae beats bioethanol, Trends Biotechnol. 26 (2008) 126-131, http://dx.doi.org/10.1016/j.tibtech.2007.12.002.

[10] Y. Chisti, Biodiesel from microalgae, Biotechnol. Adv. 25 (2007) 294-306, http://dx.doi.org/10.1016/j.biotechadv.2007.02.001.

[11] L. Rodolfi, G. Chini Zittelli, N. Bassi, G. Padovani, N. Biondi, G. Bonini, M.R. Tredici, Microalgae for oil: Strain selection, induction of lipid synthesis and outdoor mass cultivation in a low-cost photobioreactor, Biotechnol. Bioeng. 102 (2009) 100-112, doi:10.1002/bit.22033.

[12] G. Breuer, P.P. Lamers, D.E. Martens, R. Draaisma, R. Wijffels, The impact of nitrogen starvation on the dynamics of triacylglycerol accumulation in nine microalgae strains, Bioresour. Technol. 124 (2012) 217-226, http://dx.doi.org/10.1016/j.biortech.2012.08.003.

[13] P. Spolaore, C. Joannis-Cassan, E. Duran, A. Isambert, Review: commercial applications of microalgae, J. Biosci. Bioeng. 101 (2006) 87-96, http://dx.doi.org/10.1263/jbb.101.87.

[14] F. Delaunay, Y. Marty, J. Moal, J.F. Samain, The effect of monospecific algal diets on growth and fatty acid composition of Pecten maximus (L.) larvae, J. Exp. Mar. Biol. Ecol. 173 (1993) 163-179, http://dx.doi.org/10.1016/0022-0981(93)90051-O.

[15] B. Rico-Villa, J.R. Le Coz, C. Mingant, R. Robert, Influence of phytoplankton diet mixture es on microalgae consumption, larval development and settlement of the Pacific oyster Crassostrea gigas (Thunberg), Aquaculture, 256 (2006) 377-388, http://dx.doi.org/10.1016/j.aquaculture.2006.02.015. [16] J.A. Aranda-Burgos, F. da Costa, S. Nóvoa, J. Ojea, D. Martínez-Patiño, Effects of microalgal diet on growth, survival, biochemical and fatty acid composition of Ruditapes decussatus larvae, Aquaculture, 420-421 (2014) 38-48, http://dx.doi.org/10.1016/j.aquaculture.2013.10.032. 
[17] J. Knauer, P.C. Southgate, A review of the nutritional requirements of bivalves and the development of alternative and artificial diets for bivalve aquaculture, Rev. Fish. Sci. 7 (1999) 241-280, http://dx.doi.org/10.1080/10641269908951362.

[18] E.M. Bendif, I. Probert, D.C. Schroeder, C. de Vargas, On the description of Tisochrysis lutea gen. nov. sp. nov. and Isochrysis nuda sp. nov. in the Isochrysidales, and the transfer of Dicrateria to the Prymnesiales (Haptophyta), J. Appl. Phycol. 25 (2013) 1763-1776, doi:10.1007/s10811-013-0037-0. [19] J.W. Ewart, G.D. Pruder, Comparative growth of Isochrysis galbana Parke and Isochrysis aff. galbana, clone T-iso at four temperatures and three light intensities, J. World Maric. Soc. 12 (1981) 333339, doi:10.1111/j.1749-7345.1981.tb00265.x.

[20] G.E. Napolitano, R.G. Ackman, W.M.N. Ratnayake, Fatty acid composition of three cultured algal species (Isochrysis galbana, Chaetoceros gracilis and Chaetoceros calcitrans) used as food for bivalve larvae, J. World Aquacult. Soc. 21 (1990) 122-130, doi:10.1111/j.1749-7345.1990.tb00532.x.

[21] M.M. Helm, I. Laing, Preliminary observations on the nutritional value of "Tahiti Isochrysis" to bivalve larvae, Aquaculture, 62 (1987) 281-288, http://dx.doi.org/10.1016/0044-8486(87)90170-0.

[22] E. Martínez-Fernández, H. Acosta-Salmón, C. Rangel-Dávalos, Ingestion and digestion of 10 species of microalgae by winged pearl oyster Pteria sterna (Gould, 1851) larvae, Aquaculture, 230 (2004) 417 423, http://dx.doi.org/10.1016/S0044-8486(03)00416-2.

[23] S.H. Mortensen, K.Y. Borsheim, J.R. Rainuzzo, G. Knutsen, Fatty acid and elemental composition of the marine diatom Chaetoceros neogracilis Schütt. Effect of silicate deprivation, temperature and light intensity, J. Exp. Mar. Biol. Ecol. 122 (1988) 173-185, http://dx.doi.org/10.1016/0022-0981(88)90183-9. [24] A. Sukenik, R. Wahnon, Biochemical quality of marine unicellular algae with special emphasis on lipid composition. I. Isochrysis galbana, Aquaculture, 97 (1991) 61-72, http://dx.doi.org/10.1016/0044$\underline{8486(91) 90279-G}$.

[25] P.J. Harrison, P.A. Thompson, G.S. Calderwood, Effects of nutrient and light limitation on the biochemical composition of phytoplankton, J. Appl. Phycol. 2 (1990) 45-56, doi:10.1007/BF02179768. [26] P.A. Thompson, M.-X. Guo, P.J. Harrison, J.N.C. Whyte, Effects of variation in temperature. II. On the biochemical composition of eight species of marine phytoplankton, J. Phycol. 28 (1992) 488-497, doi:10.1111/j.0022-3646.1992.00481.x. 
[27] Q. Hu, M. Sommerfeld, E. Jarvis, M. Ghirardi, M. Posewitz, M. Seibert, A. Darzins, Microalgal triacylglycerols as feedstocks for biofuel production: perspectives and advances, Plant J. 54 (2008) 621639, doi:10.1111/j.1365-313X.2008.03492.x.

[28] J. Pruvost, G. Van Vooren, G. Cogne, J. Legrand, Investigation of biomass and lipids production with Neochloris oleoabundans in photobioreactor, Bioresour. Technol. 100 (2009) 5988-5995, http://dx.doi.org/10.1016/j.biortech.2009.06.004.

[29] M.J. Fernández-Reiriz, A. Pérez-Camacho, M.J. Ferreiro, J. Blanco, M. Planas, M.J. Campos, U. Labarta, Biomass production and variation in the biochemical profile (Total protein, carbohydrates, RNA, lipids and fatty acids) of seven species of marine microalgae, Aquaculture, 83 (1989) 17-37, http://dx.doi.org/10.1016/0044-8486(89)90057-4.

[30] D.L. Alonso, E.-H. Belarbi, J.M. Fernández-Sevilla, J. Rodríguez-Ruiz, E.M. Grima, Acyl lipid composition variation related to culture age and nitrogen concentration in continuous culture of the microalga Phaeodactylum tricornutum, Phytochemistry, 54 (2000) 461-471, http://dx.doi.org/10.1016/S0031-9422(00)00084-4.

[31] M. Brown, C. Garland, S. Jeffrey, I. Jameson, J. Leroi, The gross and amino acid compositions of batch and semi-continuous cultures of Isochrysis sp. (clone T.ISO), Pavlova lutheri and Nannochloropsis oculata, J. Appl. Phycol. 5 (1993) 285-296, doi:10.1007/BF02186231.

[32] G.A. Dunstan, J.K. Volkman, S.M. Barrett, C.D. Garland, Changes in the lipid composition and maximisation of the polyunsaturated fatty acid content of three microalgae grown in mass culture, J. Appl. Phycol. 5 (1993) 71-83, doi:10.1007/BF02182424.

[33] G. Bougaran, C. Rouxel, N. Dubois, R. Kaas, S. Grouas, E. Lukomska, J.-R. Le Coz, J.-P. Cadoret, Enhancement of neutral lipid productivity in the microalga Isochrysis affinis galbana (T-Iso) by a mutation-selection procedure, Biotechnol. Bioeng. 109 (2012) 2737-2745, doi:10.1002/bit.24560. [34] P. Hyka, S. Lickova, P. Přibyl, K. Melzoch, K. Kovar, Flow cytometry for the development of biotechnological processes with microalgae, Biotechnol. Adv. 31 (2013) 2-16, http://dx.doi.org/10.1016/j.biotechadv.2012.04.007.

[35] G. Carrier, M. Garnier, L. Le Cunff, G. Bougaran, I. Probert, C. De Vargas, E. Corre, J.-P. Cadoret, B. Saint-Jean, Comparative transcriptome of wild type and selected strains of the microalgae Tisochrysis lutea provides insights into the genetic basis, lipid metabolism and the life cycle, PLoS ONE, 9 (2014) e86889, https://doi.org/10.1371/journal.pone.0086889. 
[36] M. Garnier, G. Carrier, H. Rogniaux, E. Nicolau, G. Bougaran, B. Saint-Jean, J.-P. Cadoret, Comparative proteomics reveals proteins impacted by nitrogen deprivation in wild-type and high lipidaccumulating mutant strains of Tisochrysis lutea, J. Proteomics, 105 (2014) 107-120, https://doi.org/10.1016/j.jprot.2014.02.022.

[37] M. Garnier, G. Bougaran, M. Pavlovic, J.-B. Berard, G. Carrier, A. Charrier, F. Le Grand, E. Lukomska, C. Rouxel, N. Schreiber, J.-P. Cadoret, H. Rogniaux, B. Saint-Jean, Use of a lipid rich strain reveals mechanisms of nitrogen limitation and carbon partitioning in the haptophyte Tisochrysis lutea, Algal Res., 20 (2016) 229-248, https://doi.org/10.1016/j.algal.2016.10.017.

[38] F. da Costa, B. Petton, C. Mingant, G. Bougaran, C. Rouxel, C. Quéré, G.H. Wikfors, P. Soudant, R. Robert, Influence of one selected Tisochrysis lutea strain rich in lipids on Crassostrea gigas larval development and biochemical composition, Aquac. Nutr., 22 (2016) 813-836, doi:10.1111/anu.12301. [39] E.N. Powell, E.A. Bochenek, J.M. Klinck, E.E. Hofmann, Influence of food quality and quantity on the growth and development of Crassostrea gigas larvae: a modelling approach, Aquaculture, 210 (2002) 89-117, https://doi.org/10.1016/S0044-8486(01)00891-2.

[40] M.C. Haws, L. DiMichele, S.C. Hand, Biochemical changes and mortality during metamorphosis of the Eastern Oyster, Crassostrea virginica, and the Pacific oyster, Crassostrea gigas, Mol. Mar. Biol. Biotechnol, 2 (1993) 207-217.

[41] P.R. Walne, Large scale culture of larvae Ostrea edulis L., Fish Invest. II 25 (1966) 1-52.

[42] M. Levasseur, P.A. Thompson, P.J. Harrison, Physiological acclimation of marine phytoplankton to different nitrogen sources, J. Phycol. 29 (1993) 587-595, doi:10.1111/j.0022-3646.1993.00587.x.

[43] M.J.W. Veldhuis, G.W. Kraay, Vertical distribution and pigment composition of a picoplanktonic prochlorophyte in the subtropical North Atlantic: a combined study of HPLC-analysis of pigments and flow cytometry, Mar. Ecol. Prog. Ser., 68 (1990) 121-127.

[44] R.E. Holcomb, L.J. Mason, K.F. Reardon, D.M. Cropek, C.S. Henry, Culturing and investigation of stress-induced lipid accumulation in microalgae using a microfluidic device, Anal. Bioanal. Chem. 400 (2011) 245-253, doi:10.1007/s00216-011-4710-3.

[45] M. Sato, Y. Murata, M. Mizusawa, H. Iwahashi, S.-i. Oka, A simple and rapid dual-fluorescence viability assay for microalgae, Microbiol. Cult. Coll., 20 (2004) 53-59. 
[46] A. Lelong, H. Hégaret, P. Soudant, Cell-based measurements to assess physiological status of Pseudo-nitzschia multiseries, a toxic diatom, Res. Microbiol. 162 (2011) 969-981, http://dx.doi.org/10.1016/j.resmic.2011.06.005.

[47] D. Marie, F. Partensky, D. Vaulot, C. Brussaard, Enumeration of phytoplankton, bacteria, and viruses in marine samples, Curr. Protoc. Cytom. 10 (1999) 11.11:11.11.1-11.11.15, doi:10.1002/0471142956.cy1111s10.

[48] J. Folch, M. Lees, G.H.S. Stanley, A simple methods for the isolation and purification of total lipids from animal tissues, J. Biol. Chem., 226 (1957) 497-509.

[49] M. Dubois, K.A. Gilles, J.K. Hamilton, P.A. Rebers, F. Smith, Colorimetric method for determination of sugars and related substances, Anal. Chem., 28 (1956) 350-356.

[50] P. Soudant, K.V. Ryckeghem, Y. Marty, J. Moal, J.F. Samain, P. Sorgeloos, Comparison of the lipid class and fatty acid composition between a reproductive cycle in the nature and a standart hatchery conditioning of the Pacific Oyster Crassostrea gigas, Comp. Biochem. Phys. B. 123 (1999) 209-222, http://dx.doi.org/10.1016/S0305-0491(99)00063-2.

[51] P. Soudant, Y. Marty, J. Moal, J.F. Samain, Separation of major polar lipids in Pecten maximus by high-performance liquid chromatography and subsequent determination of their fatty acids using gas chromatography, J. Chromatogr. B Biomed. Sci. Appl. 673 (1995) 15-26, http://dx.doi.org/10.1016/03784347(95)00241-A.

[52] Y. Marty, F. Delaunay, J. Moal, J.F. Samain, Changes in the fatty acid composition of Pecten maximus (L.) during larval development, J. Exp. Mar. Biol. Ecol. 163 (1992) 221-234, http://dx.doi.org/10.1016/0022-0981(92)90051-B.

[53] L.D. Metcalfe, A.A. Schmitz, The rapid preparation of fatty acid esters for gas chromatography analysis, Anal. Chem. 33 (1961) 363-364.

[54] P. Soudant, M.V. Sanles, C. Quere, J.R. Le Coz, Y. Marty, J. Moal, J.F. Samain, P. Sorgeloos, The use of lipid emulsions for sterol supplementation of spat of the Pacific oyster, Crassostrea gigas, Aquaculture, 184 (2000) 315-326, http://dx.doi.org/10.1016/S0044-8486(99)00323-3.

[55] R.R. Sokal, F.J. Rohlf, Biometry. The principles and practice of statistics in biological research, Third edition ed., Freeman, New York, 1995.

[56] K.R. Clarke, R.N. Gorley, PRIMER v6: user manual/tutorial (Plymouth routines in multivariate ecological research), Plymouth: Primer-E Ltd, (2006). 
[57] T. Mazzuca Sobczuk, Y. Chisti, Potential fuel oils from the microalga Choricystis minor, J. Chem. Technol. Biotechnol. 85 (2010) 100-108, doi:10.1002/jctb.2272.

[58] R.J. Geider, H.L. MacIntyre, T.M. Kana, A dynamic regulatory model of phytoplanktonic acclimation to light, nutrients, and temperature, Limnol. Oceanogr. 43 (1998) 679-694, doi: 10.4319/lo.1998.43.4.0679.

[59] J. Fabregas, C. Herrero, B. Cabezas, J. Abalde, Biomass production and biochemical composition in mass cultures of the marine microalga Isochrysis galbana Parke at varying nutrient concentrations, Aquaculture, 53 (1986) 101-113, http://dx.doi.org/10.1016/0044-8486(86)90280-2.

[60] J.P. Fidalgo, A. Cid, E. Torres, A. Sukenik, C. Herrero, Effects of nitrogen source and growth phase on proximate biochemical composition, lipid classes and fatty acid profile of the marine microalga Isochrysis galbana, Aquaculture, 166 (1998) 105-116, http://dx.doi.org/10.1016/S0044-8486(98)00278-6. [61] I.T. Marlowe, L.J. Rogers, A.J. Smith, Extent and nature of extracellular organic production by the marine coccolithophorid Hymenomonas carterae, Mar. Biol. 100 (1989) 381-391, doi:10.1007/BF00391154.

[62] U. Larsson, A. Hagström, Phytoplankton exudate release as an energy source for the growth of pelagic bacteria, Mar. Biol. 52 (1979) 199-206, doi:10.1007/BF00398133.

[63] K. Crenn, Interactions between microalgae and bacteria in the marine environment, PhD Thesis, Université Pierre et Marie Curie - Paris VI, Paris, 2016, pp. 270.

[64] J. Rumin, H. Bonnefond, B. Saint-Jean, C. Rouxel, A. Sciandra, O. Bernard, J.-P. Cadoret, G. Bougaran, The use of fluorescent Nile red and BODIPY for lipid measurement in microalgae, Biotechnol. Biofuels, 8 (2015) 42, doi:10.1186/s13068-015-0220-4.

[65] I.C. Elle, L.C.B. Olsen, D. Pultz, S.V. Rødkær, N.J. Færgeman, Something worth dyeing for: molecular tools for the dissection of lipid metabolism in Caenorhabditis elegans, FEBS letters, 584 (2010) 2183-2193, doi: 10.1016/j.febslet.2010.03.046.

[66] J.T. Cirulis, B.C. Strasser, J.A. Scott, G.M. Ross, Optimization of staining conditions for microalgae with three lipophilic dyes to reduce precipitation and fluorescence variability, Cytometry A, 81 (2012) 618-626, doi:10.1002/cyto.a.22066.

[67] M.S. Cooper, W.R. Hardin, T.W. Petersen, R.A. Cattolico, Visualizing" green oil" in live algal cells, J. Biosci. Bioeng. 109 (2010) 198-201, http://dx.doi.org/10.1016/j.jbiosc.2009.08.004. 
[68] F. Mairet, O. Bernard, P. Masci, T. Lacour, A. Sciandra, Modelling neutral lipid production by the microalga Isochrysis aff. galbana under nitrogen limitation, Bioresour. Technol. 102 (2011) 142-149, http://dx.doi.org/10.1016/j.biortech.2010.06.138.

[69] B.L. Epstein, S. D'Hondt, J.G. Quinn, J. Zhang, P.E. Hargraves, An effect of dissolved nutrient concentrations on alkenone-based temperature estimates, Paleoceanography, 13 (1998) 122-126, doi:10.1029/97PA03358.

[70] F.G. Prahl, M.A. Sparrow, G.V. Wolfe, Physiological impacts on alkenone paleothermometry, Paleoceanography, 18 (2003), 1025, doi:10.1029/2002PA000803.

[71] M.L. Eltgroth, R.L. Watwood, G.V. Wolfe, Production and cellular localization of neutral long-chain lipids in the haptophyte algae Isochrysis galbana and Emiliania huxley, J. Phycol. 41 (2005) 1000-1009, doi:10.1111/j.1529-8817.2005.00128.x.

[72] G.J.M. Versteegh, R. Riegman, J.W. de Leeuw, J.H.F. Jansen, $U^{\mathrm{K} ' 37}$ values for Isochrysis galbana as a function of culture temperature, light intensity and nutrient concentrations, Org. Geochem. 32 (2001) 785-794, http://dx.doi.org/10.1016/S0146-6380(01)00041-9.

[73] Q. Shi, H. Araie, R.K. Bakku, Y. Fukao, R. Rakwal, I. Suzuki, Y. Shiraiwa, Proteomic analysis of lipid body from the alkenone-producing marine haptophyte alga Tisochrysis lutea, Proteomics, 15 (2015) 4145-4158, doi:10.1002/pmic.201500010.

[74] I.T. Marlowe, J.C. Green, A.C. Neal, S.C. Brassell, G. Eglinton, P.A. Course, Long chain (n-C37 C39) alkenones in the Prymnesiophyceae. Distribution of alkenones and other lipids and their taxonomic significance, Brit. Phycol. J. 19 (1984) 203-216, http://dx.doi.org/10.1080/00071618400650221. [75] G.W. Patterson, E. Tsitsa-Tsardis, G.H. Wikfors, P.K. Gladu, D.J. Chitwood, D. Harrison, Sterols and alkenones of Isochrysis, Phytochemistry, 35 (1994) 1233-1236, http://dx.doi.org/10.1016/S0031$\underline{9422(00) 94826-X}$.

[76] Y. Li, D. Han, M. Sommerfeld, Q. Hu, Photosynthetic carbon partitioning and lipid production in the oleaginous microalga Pseudochlorococcum sp.(Chlorophyceae) under nitrogen-limited conditions, Bioresour. Technol. 102 (2011) 123-129, http://dx.doi.org/10.1016/j.biortech.2010.06.036.

[77] R. Robert, M.-J. Chretiennot-Dinet, R. Kaas, V. Martin-Jezequel, J. Moal, J.-R. Le Coz, J.-L. Nicolas, E. Bernard, J.-P. Connan, L. Le Dean, G.L. Gourrierec, B. Leroy, C. Quéré, Amélioration des productions phytoplanctoniques en écloserie de mollusques: caractérisation des microalgues fourrage, Rapp. Ifremer DRV/RST/RA/LPI/ 2004.05 (2004), 149 pp. http://archimer.ifremer.fr/doc/00000/1546/. 
[78] M.-A.e. Hartmann, Plant sterols and the membrane environment, Trends Plant Sci. 3 (1998) 170-175, http://dx.doi.org/10.1016/S1360-1385(98)01233-3.

[79] M.-A.e. Hartmann, P. Benveniste, [58] Plant membrane sterols: Isolation, identification, and biosynthesis, Methods Enzymol. 148 (1987) 632-650, http://dx.doi.org/10.1016/0076-6879(87)48060-9. [80] I. Tzovenis, N. De Pauw, P. Sorgeloos, Optimisation of T-ISO biomass production rich in essential fatty acids II. Effect of different light regimes on the production of fatty acids, Aquaculture, 216 (2003) 223-242, http://dx.doi.org/10.1016/S0044-8486(02)00375-7.

[81] Y. Gong, X. Guo, X. Wan, Z. Liang, M. Jiang, Triacylglycerol accumulation and change in fatty acid content of four marine oleaginous microalgae under nutrient limitation and at different culture ages, J. Basic Microbiol. 53 (2013) 29-36, doi:10.1002/jobm.201100487.

[82] Y.-H. Lin, F.-L. Chang, C.-Y. Tsao, J.-Y. Leu, Influence of growth phase and nutrient source on fatty acid composition of Isochrysis galbana CCMP 1324 in a batch photoreactor, Biochem. Eng. J. 37 (2007) 166-176, http://dx.doi.org/10.1016/j.bej.2007.04.014.

[83] R. Huerlimann, E.J. Steinig, H. Loxton, K.R. Zenger, D.R. Jerry, K. Heimann, The effect of nitrogen limitation on acetyl-CoA carboxylase expression and fatty acid content in Chromera velia and Isochrysis aff. galbana (TISO), Gene, 543 (2014) 204-211, http://dx.doi.org/10.1016/j.gene.2014.04.022.

[84] H.M. Guzmán, A. de la Jara Valido, L.C. Duarte, K.F. Presmanes, Analysis of interspecific variation in relative fatty acid composition: use of flow cytometry to estimate unsaturation index and relative polyunsaturated fatty acid content in microalgae, J. Appl. Phycol. 23 (2011) 7-15, doi:10.1007/s10811010-9526-6.

[85] G.W. O'Neil, A.R. Culler, J.R. Williams, N.P. Burlow, G.J. Gilbert, C.A. Carmichael, R.K. Nelson, R.F. Swarthout, C.M. Reddy, Production of jet fuel range hydrocarbons as a coproduct of algal biodiesel by butenolysis of long-chain alkenones, Energy Fuels, 29 (2015) 922-930, doi: 10.1021/ef502617z.

[86] A.P. Simopoulos, Essential fatty acids in health and chronic disease, Am. J. Clin. Nutr. 70 (1999) 560s-569s.

[87] T. Tonon, D. Harvey, T.R. Larson, I.A. Graham, Long chain polyunsaturated fatty acid production and partitioning to triacylglycerols in four microalgae, Phytochemistry, 61 (2002) 15-24, http://dx.doi.org/10.1016/S0031-9422(02)00201-7.

[88] K.I. Reitan, J.R. Rainuzzo, Y. Olsen, Effect of nutrient limitation on fatty acid and lipid content of marine microalgae, J. Phycol. 30 (1994) 972-979, doi:10.1111/j.0022-3646.1994.00972.x. 
[89] B. Gilbert-López, J.A. Mendiola, J. Fontecha, L.A.M. van den Broek, L. Sijtsma, A. Cifuentes, M. Herrero, E. Ibáñez, Downstream processing of Isochrysis galbana: a step towards microalgal biorefinery, Green Chem. 17 (2015) 4599-4609, doi: 10.1039/C5GC01256B.

[90] E. Valenzuela-Espinoza, R. Millán-Núñez, F. Núñez-Cebrero, Protein, carbohydrate, lipid and chlorophyll a content in Isochrysis aff. galbana (clone T-Iso) cultured with a low cost alternative to the f/2 medium, Aquacult. Eng. 25 (2002) 207-216, http://dx.doi.org/10.1016/S0144-8609(01)00084-X. 


\section{Figures}
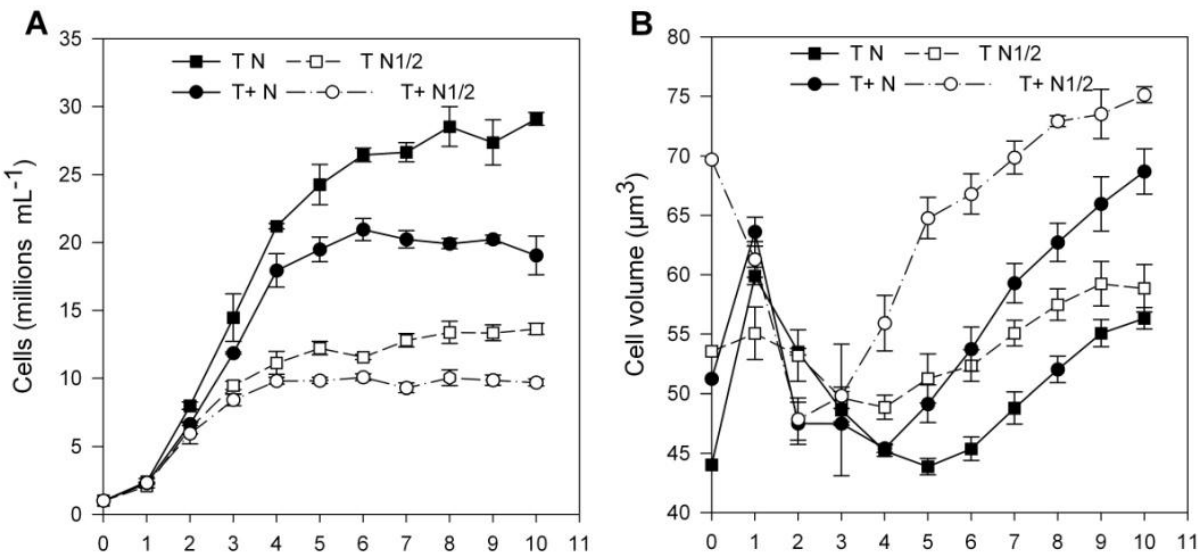

C

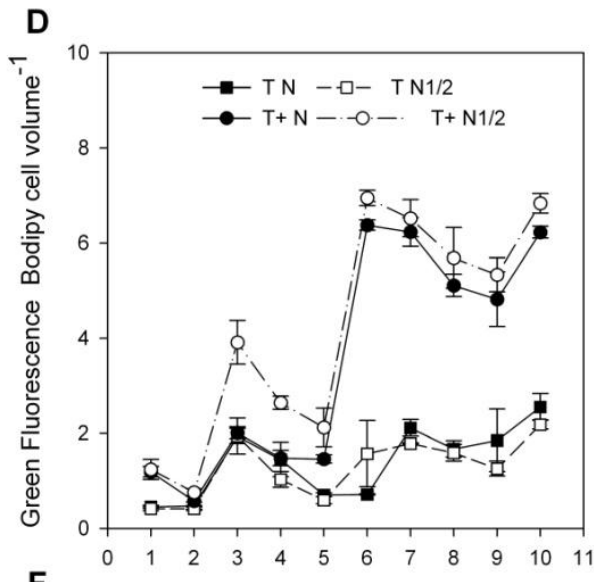

E

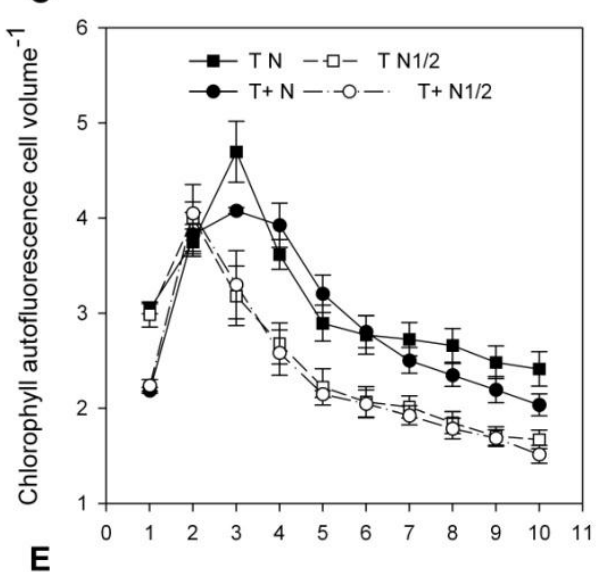

$\mathbf{F}$
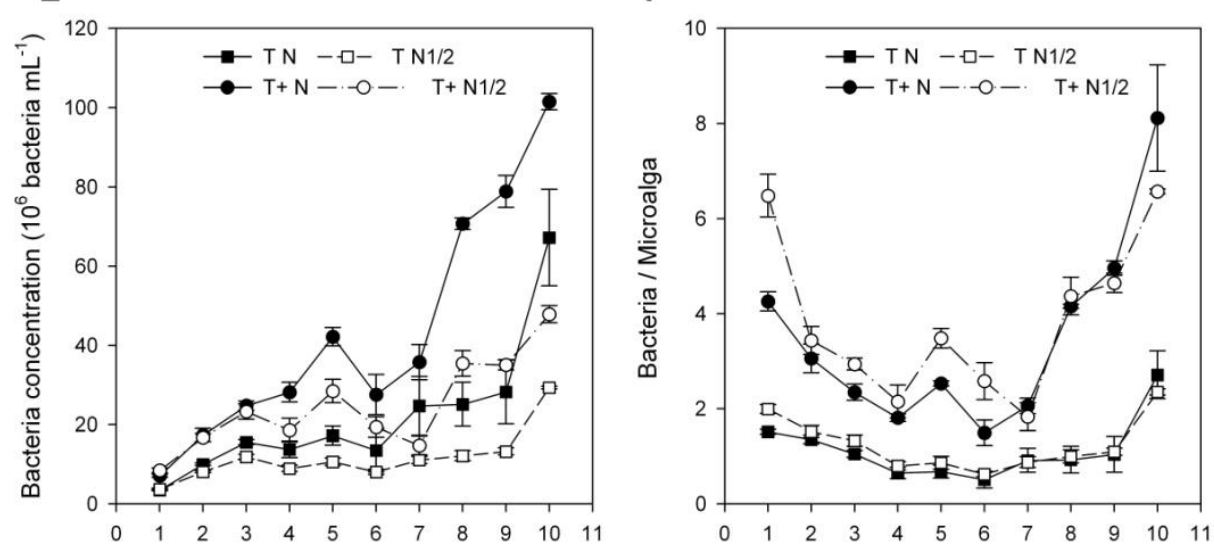

Fig. 1. Microalgal growth, morphological and physiological characteristics of $\mathbf{T}=$ Tisochrysis lutea -

standard type and $\mathbf{T}+=T$. lutea - selected strain grown in N-replete $(\mathrm{N})$ and N-reduced conditions (N1/2) during 10 days of experiment (Mean \pm S.D., $\mathrm{n}=3$ ). A. Microalgal growth (million cells $\mathrm{mL}^{-1}$ ). B. Cell volume $\left(\mu \mathrm{m}^{3}\right)$. C. Relative chlorophyll autofluorescence per cell volume. D. Green fluorescence of microalgal cells stained with Bodipy 493/50 per cell volume (indicator of lipid content) and E. Bacteria concentration after staining with SybrGreen I $\left(10^{6}\right.$ bacteria $\left.\mathrm{mL}^{-1}\right)$. F. Bacteria / microalga ratio. 

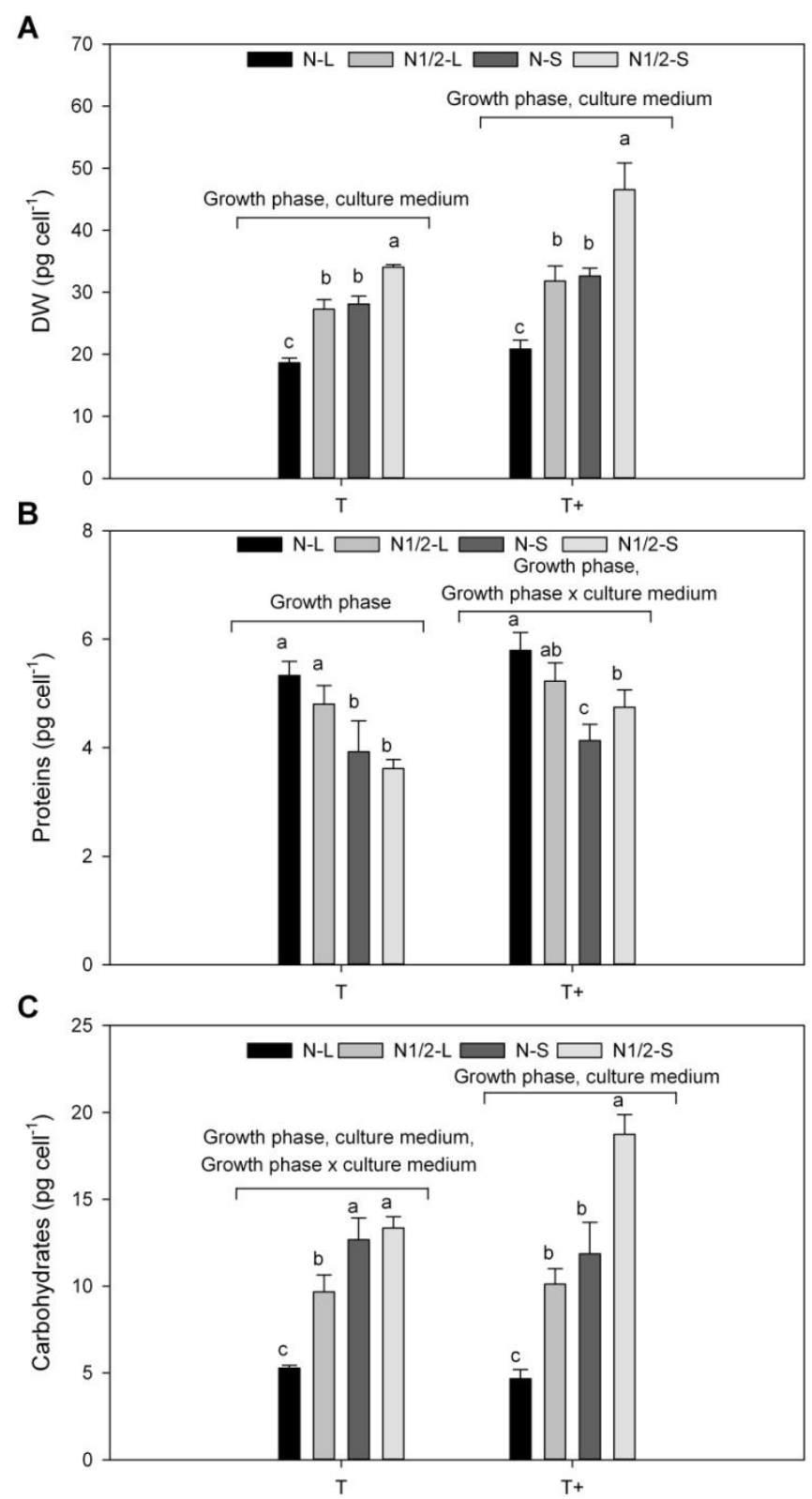

Fig. 2. Dry weight and proximate biochemical composition of $\mathbf{T}=$ Tisochrysis lutea - standard type and $\mathbf{T}+=T$. lutea - selected strain grown in N-replete $(\mathrm{N})$ and N-reduced conditions (N1/2) in logarithmic phase (L) and stationary phase (S) (Mean \pm S.D., $n=3)$. A. Dry weight (DW). B. Proteins expressed in pg cell ${ }^{-1}$. C. Carbohydrates expressed in $\mathrm{pg}$ cell $^{-1}$.

For each strain, the annotations "growth phase", "culture medium" or "growth phase x culture medium" respectively indicate that growth phase, $\mathrm{N}$ level in culture medium or their interaction have significant effects on the tested parameter (Two-way ANOVA, $\mathrm{p}<0.05$ ). Values with same letters are not significantly different at $P<0.05$. 

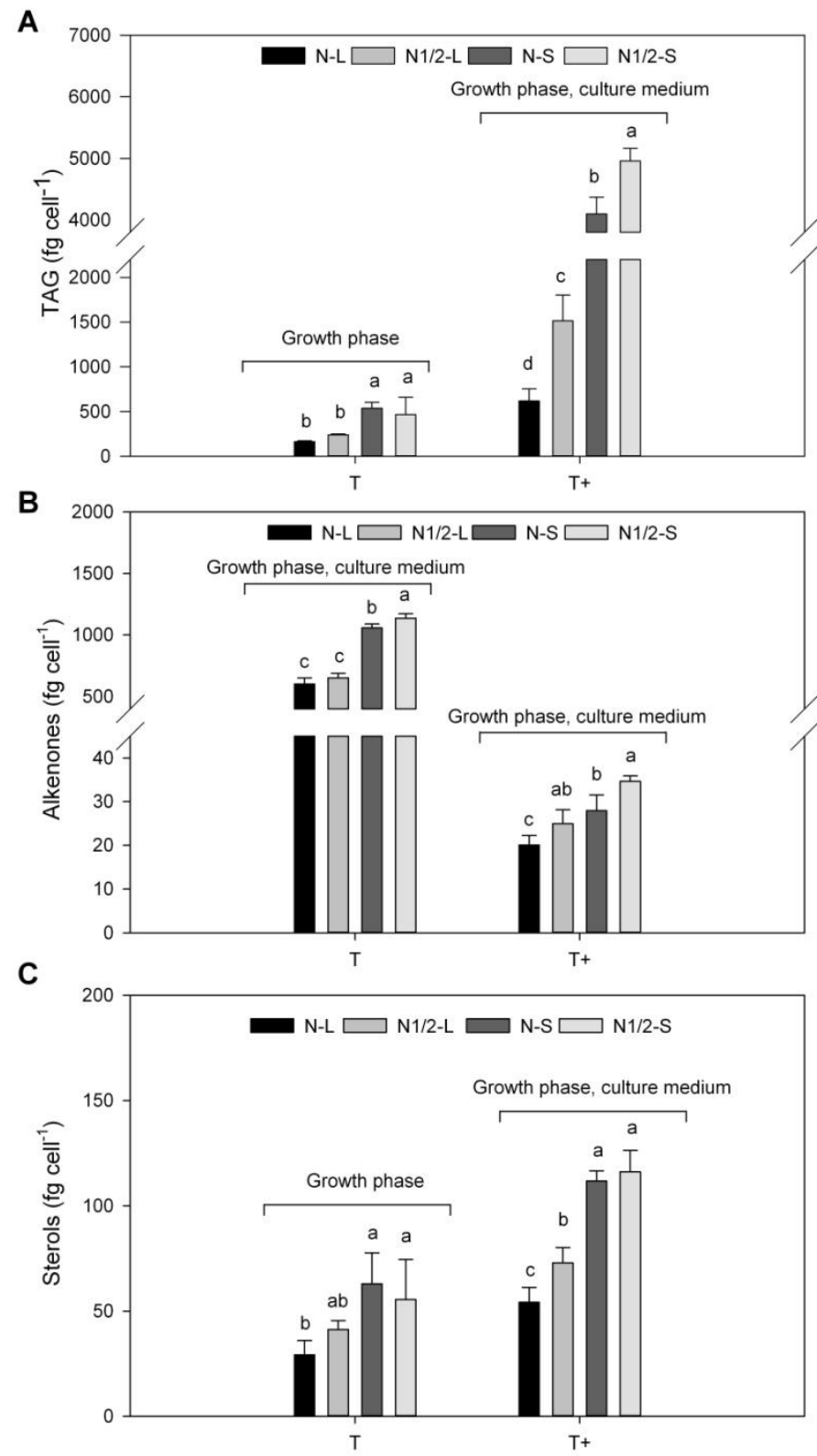

Fig. 3. (A) Total triacylglycerol (TAG), (B) alkenones (sum of the bands ALK a and ALK b) and (C) total sterol cell content determined by HPTLC of $\mathbf{T}=$ Tisochrysis lutea - standard type and $\mathbf{T}+=$ T. lutea - selected strains grown in N-replete (N) and N-reduced conditions (N1/2) in logarithmic phase (L) and stationary phase $(S)($ Mean \pm S.D., $n=3)$. For each strain, the annotations "growth phase", "culture medium" or "growth phase x culture medium" respectively indicate that growth phase, $\mathrm{N}$ level in culture medium or their interaction have significant effects on the tested parameter (Two-way ANOVA, $\mathrm{p}<0.05$ ). Values with same letters are not significantly different at $P<0.05$. 

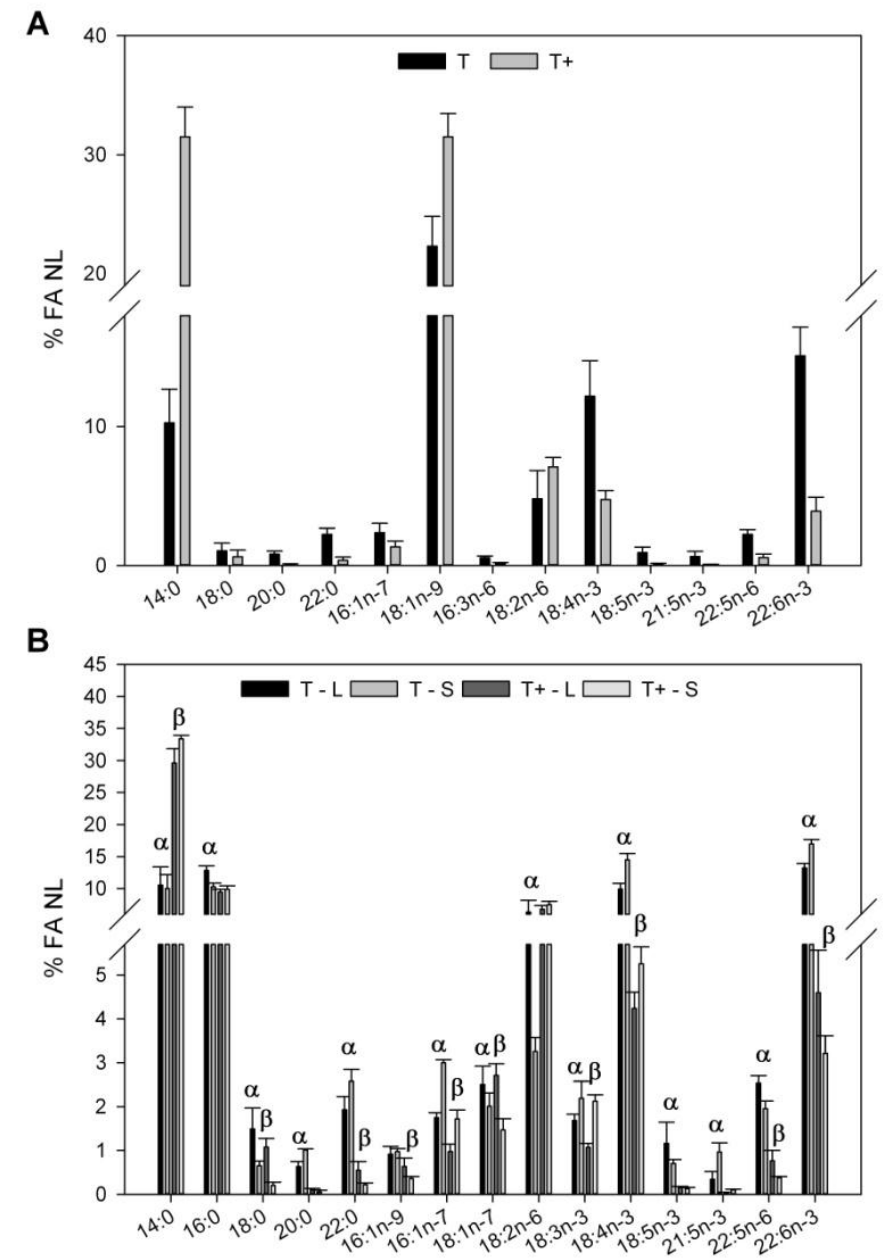

Fig. 4. Fatty acid composition of neutral lipids (expressed in weight \% of total FA in neutral lipid fraction). A. Main NL fatty acids contributing to the differences in fatty acid profile detected with SIMPER between $\mathbf{T}=$ Tisochrysis lutea - standard type and $\mathbf{T}+=T$. lute - selected strain using pooled data (Mean \pm S.D., $n=12$ ). B. Main NL fatty acids contributing to the differences in fatty acid profile between logarithmic phase (L) and stationary phase (S) detected with SIMPER for each T. lutea strain. FA contributing to changes linked to growth phase were identified with $\alpha$ and $\beta$ for $\mathbf{T}$ and $\mathbf{T}+$, respectively (Mean \pm S.D., $\mathrm{n}=6$ ). 

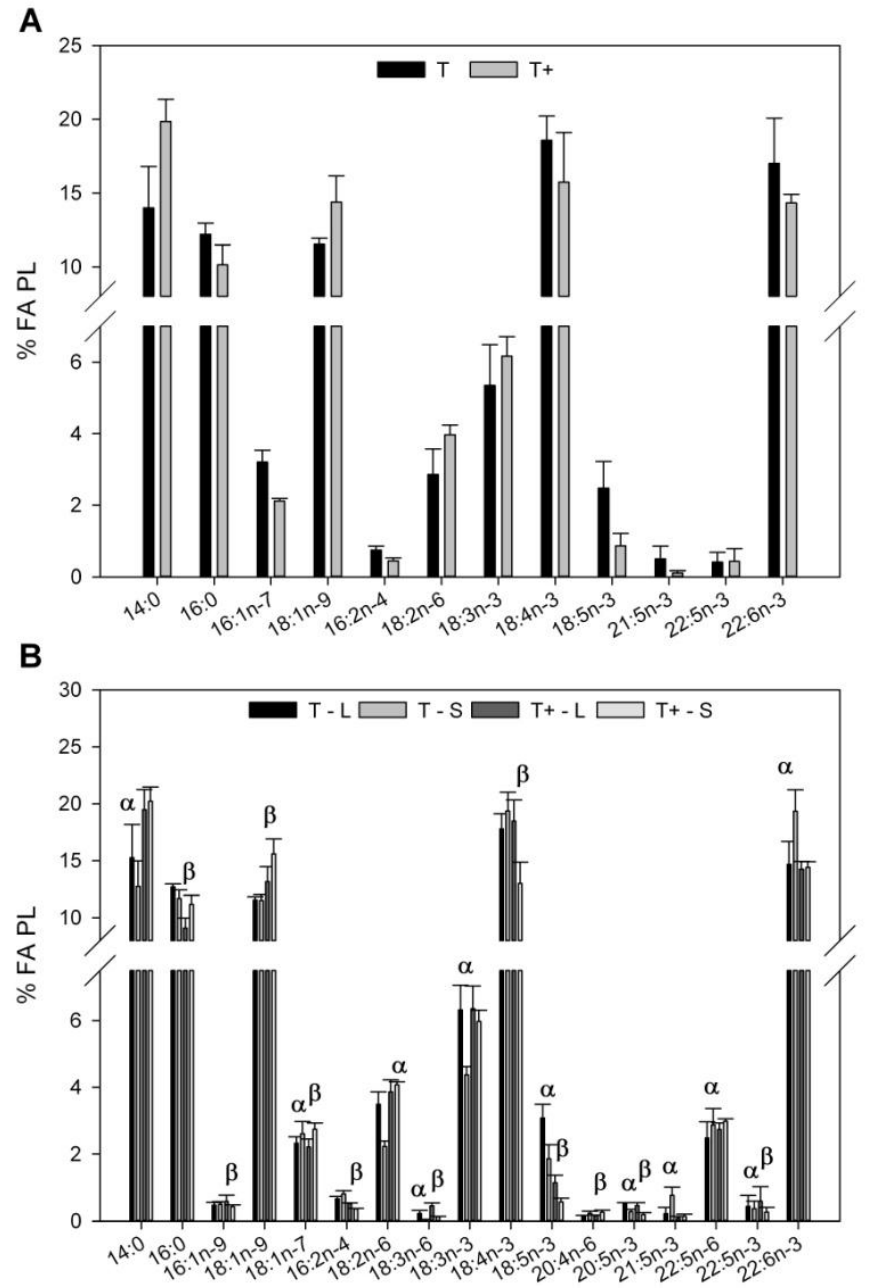

Fig. 5. Fatty acid composition of polar lipids (expressed in weight $\%$ of total FA in polar lipid fraction).

A. Main fatty acids contributing to the differences in fatty acid profile detected with SIMPER between $\mathbf{T}$ $=$ Tisochrysis lutea - standard type and $\mathbf{T}+=T$. lutea - selected strain using pooled data (Mean \pm S.D., $\mathrm{n}=12$ ). B. Main fatty acids contributing to the differences in fatty acid profile between logarithmic phase (L) and stationary phase (S) detected with SIMPER for each T. lutea strain. FA contributing to changes linked to growth phase were identified with $\alpha$ and $\beta$ for $\mathbf{T}$ and $\mathbf{T}+$, respectively (Mean \pm S.D., $n=6$ ). 


\section{Table 1}

Percentage of dead cells stained by Sytox Green of $\mathbf{T}=$ Tisochrysis lutea - standard type and $\mathbf{T}+=T$.

lutea - selected strain grown in N-replete (N) and N-reduced conditions (N1/2) during 10 days of experiment determined by FCM (Mean \pm S.D., $\mathrm{n}=3$ ).

\begin{tabular}{rrrrr}
\hline Day & T N & T N1/2 & T+ & T+ N1/2 \\
\hline 1 & $0.0 \pm 0.0$ & $0.4 \pm 0.4$ & $0.7 \pm 0.4$ & $0.5 \pm 0.3$ \\
2 & $0.0 \pm 0.0$ & $0.1 \pm 0.1$ & $0.1 \pm 0.1$ & $0.1 \pm 0.1$ \\
3 & $0.0 \pm 0.0$ & $0.2 \pm 0.0$ & $0.3 \pm 0.1$ & $0.2 \pm 0.2$ \\
4 & $0.1 \pm 0.1$ & $0.1 \pm 0.0$ & $0.1 \pm 0.0$ & $0.2 \pm 0.1$ \\
5 & $0.1 \pm 0.1$ & $0.3 \pm 0.2$ & $0.1 \pm 0.1$ & $0.2 \pm 0.1$ \\
6 & $0.5 \pm 0.4$ & $0.4 \pm 0.1$ & $0.3 \pm 0.1$ & $0.5 \pm 0.2$ \\
7 & $0.3 \pm 0.1$ & $0.4 \pm 0.2$ & $0.4 \pm 0.0$ & $0.8 \pm 0.3$ \\
8 & $0.3 \pm 0.1$ & $0.4 \pm 0.2$ & $0.4 \pm 0.2$ & $0.6 \pm 0.1$ \\
9 & $0.2 \pm 0.1$ & $0.5 \pm 0.2$ & $0.2 \pm 0.2$ & $0.5 \pm 0.2$ \\
10 & $0.5 \pm 0.3$ & $0.4 \pm 0.3$ & $14.2 \pm 7.7$ & $15.7 \pm 5.4$ \\
\hline
\end{tabular}




\section{Table 2}

Results of neutral lipid class composition (expressed in \% of the NL \pm S.D., $\mathrm{n}=3$ ) and summary of the 2-way analysis of variance (ANOVA) of T $=$ Tisochrysis lutea standard type and $\mathbf{T}+=T$. lutea - selected strain grown under N-replete (N) and N-reduced conditions (N1/2) in logarithmic (L) and stationary phases (S). Significant probabilities for 2-way ANOVA are in bold $(P<0.05)$. AL: Alcohols; ALK: alkenones (sum of ALK a + ALK b); StE + HC: sum of sterol esters and hydrocarbons; FFA: free fatty acids; ST: sterols; TAG: triacylglycerols. Cell content in total neutral lipids (NL) expressed in fg cell ${ }^{-1}$. Mean not sharing a common superscript are significantly different $(P<0.05)$.

\begin{tabular}{|c|c|c|c|c|c|c|c|c|c|}
\hline Strain & Growth phase & Medium & $\mathrm{StE}+\mathrm{HC}(\%)$ & TAG $(\%)$ & FFA $(\%)$ & $\mathrm{AL}(\%)$ & $\mathrm{ST}(\%)$ & ALK (\%) & Total NL (fg cell $\left.{ }^{-1}\right)$ \\
\hline \multirow{4}{*}{$\mathbf{T}$} & $\mathrm{L}$ & $\mathrm{N}$ & $1.6 \pm 0.1^{\mathrm{c}}$ & $18.8 \pm 1.1^{\mathrm{c}}$ & $9.5 \pm 1.0^{\mathrm{a}}$ & $0.0 \pm 0.0^{\mathrm{c}}$ & $3.3 \pm 0.6$ & $68.4 \pm 1.6^{\mathrm{a}}$ & $879.8 \pm 61.5^{b}$ \\
\hline & $\mathrm{L}$ & $\mathrm{N} 1 / 2$ & $2.9 \pm 0.2^{b}$ & $23.6 \pm 0.6^{\mathrm{b}}$ & $8.3 \pm 1.4^{\mathrm{ab}}$ & $0.0 \pm 0.0^{c}$ & $4.0 \pm 0.4$ & $64.1 \pm 1.5^{\mathrm{ab}}$ & $1018.3 \pm 36.3^{\mathrm{b}}$ \\
\hline & $\mathrm{S}$ & $\mathrm{N}$ & $3.5 \pm 0.3^{b}$ & $30.5 \pm 3.0^{\mathrm{a}}$ & $5.9 \pm 1.8^{\mathrm{b}}$ & $0.3 \pm 0.0^{\mathrm{ab}}$ & $3.6 \pm 0.8$ & $59.9 \pm 3.1^{\mathrm{b}}$ & $1767.5 \pm 41.2^{\mathrm{a}}$ \\
\hline & $\mathrm{S}$ & $\mathrm{N} 1 / 2$ & $4.8 \pm 1.1^{\mathrm{a}}$ & $30.1 \pm 3.9^{\mathrm{a}}$ & $5.6 \pm 0.8^{\mathrm{b}}$ & $0.3 \pm 0.0^{\mathrm{a}}$ & $2.9 \pm 0.7$ & $61.1 \pm 3.8^{\mathrm{b}}$ & $1867.5 \pm 198.7^{\mathrm{a}}$ \\
\hline \multicolumn{10}{|c|}{ Source of variation } \\
\hline \multicolumn{2}{|c|}{ A: Growth phase } & & 0.000 & 0.000 & 0.009 & 0.000 & 0.900 & 0.006 & 0.000 \\
\hline \multicolumn{2}{|c|}{ B: Medium } & & 0.001 & 0.129 & 0.471 & 0.043 & 0.309 & 0.324 & 0.060 \\
\hline \multicolumn{2}{|l|}{$\mathrm{AB}$} & & 0.482 & 0.088 & 0.632 & 0.043 & 0.124 & 0.112 & 0.729 \\
\hline \multirow{4}{*}{$\mathbf{T}+$} & $\mathrm{L}$ & $\mathrm{N}$ & $2.0 \pm 0.2^{\mathrm{c}}$ & $80.6 \pm 2.4^{\mathrm{c}}$ & $9.6 \pm 1.8^{\mathrm{a}}$ & $0.0 \pm 0.0^{\mathrm{c}}$ & $7.2 \pm 0.9^{\mathrm{a}}$ & $2.6 \pm 0.2^{\mathrm{a}}$ & $765.7 \pm 144.7^{\mathrm{d}}$ \\
\hline & $\mathrm{L}$ & $\mathrm{N} 1 / 2$ & $1.8 \pm 0.2^{\mathrm{c}}$ & $90.7 \pm 1.0^{\mathrm{b}}$ & $3.4 \pm 0.5^{b}$ & $0.0 \pm 0.0^{\mathrm{c}}$ & $4.4 \pm 0.3^{\mathrm{b}}$ & $1.5 \pm 0.2^{b}$ & $1668.8 \pm 297.9^{c}$ \\
\hline & $\mathrm{S}$ & $\mathrm{N}$ & $3.2 \pm 0.1^{\mathrm{b}}$ & $94.1 \pm 1.0^{\mathrm{a}}$ & $2.4 \pm 1.0^{\mathrm{bc}}$ & $0.2 \pm 0.0^{\mathrm{b}}$ & $2.6 \pm 0.2^{\mathrm{c}}$ & $0.6 \pm 0.1^{\mathrm{c}}$ & $4352.4 \pm 239.1^{b}$ \\
\hline & $\mathrm{S}$ & $\mathrm{N} 1 / 2$ & $4.5 \pm 0.2^{\mathrm{a}}$ & $95.4 \pm 0.1^{\mathrm{a}}$ & $1.4 \pm 0.3^{\mathrm{c}}$ & $0.3 \pm 0.0^{\mathrm{a}}$ & $2.2 \pm 0.2^{\mathrm{c}}$ & $0.7 \pm 0.0^{\mathrm{c}}$ & $5196.6 \pm 222.1^{\mathrm{a}}$ \\
\hline \multicolumn{10}{|c|}{ Source of variation } \\
\hline \multicolumn{2}{|c|}{ A: Growth phase } & & 0.000 & 0.000 & 0.000 & 0.000 & 0.000 & 0.000 & 0.000 \\
\hline \multicolumn{2}{|c|}{ B: Medium } & & 0.003 & 0.000 & 0.000 & 0.000 & 0.000 & 0.000 & 0.000 \\
\hline \multicolumn{2}{|l|}{$\mathrm{AB}$} & & 0.001 & 0.001 & 0.012 & 0.000 & 0.005 & 0.000 & 0.832 \\
\hline
\end{tabular}


Table 3 Productivity ( $\mathrm{mg} \mathrm{L}^{-1}$ day $^{-1}$ ) of the main components of $\mathbf{T}=$ Tisochrysis lutea - standard type and $\mathbf{T}+=T$. lutea - selected strain grown under $\mathrm{N}$-replete $(\mathrm{N})$ and $\mathrm{N}$-reduced conditions $(\mathrm{N} 1 / 2)$ at logarithmic and stationary phase.

\begin{tabular}{lcccccccc}
\hline & \multicolumn{3}{c}{ Logarithmic phase } & \multicolumn{3}{c}{ Stationary phase } \\
\cline { 2 - 10 } & \multicolumn{3}{c}{$\mathrm{T}$} & \multicolumn{2}{c}{$\mathrm{T}+$} & \multicolumn{2}{c}{$\mathrm{T}$} & \multicolumn{2}{c}{$\mathrm{T}+$} \\
\cline { 2 - 10 } & $\mathrm{N}$ & $\mathrm{N} 1 / 2$ & $\mathrm{~N}$ & $\mathrm{~N} 1 / 2$ & $\mathrm{~N}$ & $\mathrm{~N} 1 / 2$ & $\mathrm{~N}$ & $\mathrm{~N} 1 / 2$ \\
\hline Dry weight & 98.8 & 76.1 & 93.5 & 78.1 & 81.8 & 46.5 & 62.2 & 45.1 \\
Proteins & 28.3 & 25.5 & 30.7 & 27.7 & 8.3 & 7.7 & 8.8 & 10.1 \\
Carbohydrates & 27.9 & 51.3 & 24.8 & 53.6 & 26.9 & 28.3 & 25.2 & 39.8 \\
Total lipids & 20.6 & 23.9 & 22.1 & 29.5 & 8.7 & 9.6 & 16.5 & 19.7 \\
Neutral lipids & 4.7 & 5.4 & 4.1 & 8.9 & 3.7 & 4.0 & 9.2 & 11.0 \\
Triacylglycerol (TAG) & 0.9 & 1.3 & 3.3 & 8.0 & 1.1 & 1.0 & 8.7 & 10.5 \\
Alkenones & 3.2 & 3.5 & 0.1 & 0.1 & 2.2 & 2.4 & 0.1 & 0.1 \\
DHA & 1.1 & 0.6 & 1.0 & 0.6 & 0.8 & 0.4 & 0.6 & 0.3 \\
\hline
\end{tabular}




\section{Supplementary Table 1}

Fatty acid composition of neutral lipids (expressed wt\% of total FA in neutral lipid fraction \pm S.D., $n=3$ ) of $\mathbf{T}=$ Tisochrysis lutea - standard type grown under N-replete (N) and N-reduced conditions (N1/2) on day 4 and day 10. $\sum$ SFA: Total saturated fatty acids; $\sum$ MUFA: Total monounsaturated fatty acids; $\sum$ PUFA: Total polyunsaturated fatty acids. Fatty acids representing less than $0.5 \%$ of total fatty acids were excluded from the list.

\begin{tabular}{|c|c|c|c|c|}
\hline & \multicolumn{2}{|c|}{ Day 4} & \multicolumn{2}{|c|}{ Day 10} \\
\hline & $\mathrm{N}$ & $\mathrm{N} 1 / 2$ & $\mathrm{~N}$ & $\mathrm{~N} 1 / 2$ \\
\hline $14: 0$ & $13.1 \pm 0.3$ & $7.9 \pm 0.4$ & $11.9 \pm 0.6$ & $8.1 \pm 0.4$ \\
\hline $16: 0$ & $12.3 \pm 0.6$ & $13.4 \pm 0.3$ & $10.6 \pm 0.6$ & $10.0 \pm 0.4$ \\
\hline $18: 0$ & $1.2 \pm 0.1$ & $1.8 \pm 0.5$ & $0.6 \pm 0.0$ & $0.7 \pm 0.1$ \\
\hline $20: 0$ & $0.5 \pm 0.0$ & $0.7 \pm 0.1$ & $1.0 \pm 0.0$ & $1.0 \pm 0.0$ \\
\hline $22: 0$ & $1.7 \pm 0.1$ & $2.2 \pm 0.1$ & $2.3 \pm 0.1$ & $2.8 \pm 0.1$ \\
\hline $16: 1 n-9$ & $0.9 \pm 0.3$ & $0.9 \pm 0.1$ & $0.9 \pm 0.0$ & $1.0 \pm 0.1$ \\
\hline $16: 1 n-7$ & $1.8 \pm 0.1$ & $1.7 \pm 0.1$ & $3.0 \pm 0.1$ & $3.0 \pm 0.1$ \\
\hline $18: 1 n-9$ & $23.0 \pm 1.5$ & $25.5 \pm 1.2$ & $19.5 \pm 1.0$ & $21.2 \pm 0.2$ \\
\hline $18: 1 n-7$ & $2.5 \pm 0.4$ & $2.5 \pm 0.5$ & $2.3 \pm 0.1$ & $1.7 \pm 0.0$ \\
\hline $16: 3 n-6$ & $0.6 \pm 0.1$ & $0.6 \pm 0.1$ & $0.6 \pm 0.1$ & $0.4 \pm 0.0$ \\
\hline $18: 2 n-6$ & $4.7 \pm 0.4$ & $8.0 \pm 0.6$ & $3.0 \pm 0.2$ & $3.5 \pm 0.1$ \\
\hline $18: 3 n-3$ & $1.6 \pm 0.1$ & $1.8 \pm 0.1$ & $1.8 \pm 0.1$ & $2.5 \pm 0.1$ \\
\hline $18: 4 n-3$ & $10.5 \pm 0.9$ & $9.4 \pm 0.6$ & $13.6 \pm 0.3$ & $15.4 \pm 0.3$ \\
\hline $18: 5 n-3$ & $1.6 \pm 0.2$ & $0.7 \pm 0.1$ & $0.8 \pm 0.0$ & $0.6 \pm 0.0$ \\
\hline $20: 5 n-3$ & $0.4 \pm 0.1$ & $0.5 \pm 0.1$ & $0.5 \pm 0.0$ & $0.7 \pm 0.0$ \\
\hline $21: 5 n-3$ & $0.2 \pm 0.0$ & $0.5 \pm 0.1$ & $0.8 \pm 0.1$ & $1.1 \pm 0.2$ \\
\hline $22: 5 n-6$ & $2.5 \pm 0.1$ & $2.6 \pm 0.2$ & $2.1 \pm 0.2$ & $1.8 \pm 0.0$ \\
\hline $22: 6 n-3$ & $13.2 \pm 1.1$ & $13.3 \pm 0.1$ & $17.0 \pm 0.9$ & $16.9 \pm 0.6$ \\
\hline$\sum$ SFAs & $31.2 \pm 2.7$ & $26.9 \pm 0.5$ & $28.1 \pm 1.7$ & $23.2 \pm 0.5$ \\
\hline$\sum$ MUFAs & $29.7 \pm 0.2$ & $32.3 \pm 1.7$ & $27.2 \pm 0.6$ & $28.8 \pm 0.2$ \\
\hline$\sum n-9$ & $24.8 \pm 0.7$ & $27.8 \pm 1.2$ & $20.7 \pm 0.7$ & $23.1 \pm 0.1$ \\
\hline$\sum \mathrm{n}-7$ & $4.7 \pm 0.6$ & $4.5 \pm 0.6$ & $5.9 \pm 0.0$ & $5.2 \pm 0.1$ \\
\hline$\sum$ PUFAs & $39.0 \pm 2.7$ & $40.7 \pm 1.2$ & $44.6 \pm 1.2$ & $47.9 \pm 0.6$ \\
\hline$\sum n-4$ & $0.3 \pm 0.0$ & $0.2 \pm 0.0$ & $0.5 \pm 0.1$ & $0.5 \pm 0.0$ \\
\hline$\sum n-6$ & $9.1 \pm 0.7$ & $12.9 \pm 0.8$ & $8.1 \pm 0.3$ & $8.6 \pm 0.2$ \\
\hline$\sum n-3$ & $28.5 \pm 1.8$ & $26.8 \pm 0.7$ & $35.5 \pm 0.9$ & $38.3 \pm 0.8$ \\
\hline$n-3 / n-6$ & $3.1 \pm 0.1$ & $2.1 \pm 0.2$ & $4.4 \pm 0.1$ & $4.5 \pm 0.2$ \\
\hline $22: 6 / 20: 5$ & $34.2 \pm 6.6$ & $26.6 \pm 3.4$ & $35.7 \pm 3.5$ & $23.9 \pm 1.0$ \\
\hline $22: 5 / 20: 4$ & $17.4 \pm 1.1$ & $12.0 \pm 2.3$ & $13.7 \pm 1.0$ & $9.5 \pm 2.0$ \\
\hline Total $\left(\right.$ fg cell $\left.{ }^{-1}\right)$ & $317.9 \pm 34.1$ & $303.0 \pm 22.4$ & $569.3 \pm 10.6$ & $606.2 \pm 118.2$ \\
\hline
\end{tabular}




\section{Supplementary Table 2}

Fatty acid composition of neutral lipids (expressed wt\% of total FA in neutral lipid fraction \pm S.D., $n=3$ ) of $\mathbf{T}+=$ Tisochrysis lutea - selected strain grown under N-replete $(\mathrm{N})$ and N-reduced conditions (N1/2) on day 4 and day 10. $\sum$ SFA: Total saturated fatty acids; $\sum$ MUFA: Total monounsaturated fatty acids; $\sum$ PUFA: Total polyunsaturated fatty acids. Fatty acids representing less than $0.5 \%$ of total fatty acids were excluded from the list.

\begin{tabular}{|c|c|c|c|c|}
\hline & \multicolumn{2}{|c|}{ Day 4} & \multicolumn{2}{|c|}{ Day 10} \\
\hline & $\mathrm{N}$ & $\mathrm{N} 1 / 2$ & $\mathrm{~N}$ & $\mathrm{~N} 1 / 2$ \\
\hline $14: 0$ & $28.1 \pm 2.6$ & $31.1 \pm 0.8$ & $33.2 \pm 0.1$ & $33.1 \pm 0.8$ \\
\hline $16: 0$ & $9.2 \pm 0.6$ & $9.7 \pm 0.1$ & $9.4 \pm 0.2$ & $10.2 \pm 0.2$ \\
\hline 18:0 & $1.2 \pm 0.2$ & $0.9 \pm 0.1$ & $0.3 \pm 0.1$ & $0.2 \pm 0.0$ \\
\hline $22: 0$ & $0.7 \pm 0.2$ & $0.4 \pm 0.2$ & $0.2 \pm 0.0$ & $0.2 \pm 0.1$ \\
\hline $16: 1 n-9$ & $0.7 \pm 0.4$ & $0.6 \pm 0.3$ & $0.4 \pm 0.0$ & $0.3 \pm 0.1$ \\
\hline $16: 1 n-7$ & $0.8 \pm 0.2$ & $1.1 \pm 0.1$ & $1.6 \pm 0.0$ & $1.9 \pm 0.1$ \\
\hline $18: 1 n-9$ & $33.3 \pm 1.2$ & $32.7 \pm 0.7$ & $29.2 \pm 0.8$ & $30.4 \pm 1.7$ \\
\hline $18: 1 n-7$ & $2.6 \pm 0.4$ & $2.8 \pm 0.3$ & $1.6 \pm 0.1$ & $1.4 \pm 0.4$ \\
\hline $18: 2 n-6$ & $6.6 \pm 0.4$ & $6.8 \pm 0.7$ & $7.9 \pm 0.0$ & $6.9 \pm 0.3$ \\
\hline $18: 3 n-3$ & $1.1 \pm 0.0$ & $1.0 \pm 0.1$ & $2.1 \pm 0.1$ & $2.1 \pm 0.2$ \\
\hline $18: 4 n-3$ & $4.4 \pm 0.5$ & $4.1 \pm 0.1$ & $5.1 \pm 0.3$ & $5.3 \pm 0.4$ \\
\hline $22: 5 n-6$ & $1.0 \pm 0.3$ & $0.6 \pm 0.0$ & $0.4 \pm 0.0$ & $0.4 \pm 0.0$ \\
\hline $22: 6 n-3$ & $5.5 \pm 0.9$ & $3.7 \pm 0.2$ & $3.4 \pm 0.3$ & $3.0 \pm 0.4$ \\
\hline$\sum$ SFAs & $39.8 \pm 2.1$ & $42.7 \pm 0.7$ & $43.7 \pm 0.0$ & $44.2 \pm 1.0$ \\
\hline$\sum$ MUFAs & $39.0 \pm 1.2$ & $38.2 \pm 0.3$ & $34.0 \pm 0.9$ & $35.0 \pm 1.6$ \\
\hline$\sum n-9$ & $34.8 \pm 1.3$ & $33.2 \pm 0.4$ & $29.7 \pm 0.7$ & $30.9 \pm 1.9$ \\
\hline$\sum n-7$ & $4.0 \pm 0.6$ & $4.2 \pm 0.4$ & $3.9 \pm 0.1$ & $4.1 \pm 0.4$ \\
\hline$\sum$ PUFAs & $20.8 \pm 1.1$ & $18.8 \pm 0.6$ & $21.8 \pm 0.9$ & $20.4 \pm 1.0$ \\
\hline$\sum n-4$ & $0.1 \pm 0.0$ & $0.1 \pm 0.0$ & $0.2 \pm 0.1$ & $0.2 \pm 0.0$ \\
\hline$\sum n-6$ & $8.7 \pm 0.3$ & $8.9 \pm 0.9$ & $9.9 \pm 0.0$ & $8.8 \pm 0.3$ \\
\hline$\sum n-3$ & $11.7 \pm 1.2$ & $9.4 \pm 0.2$ & $11.4 \pm 0.9$ & $11.2 \pm 1.1$ \\
\hline$n-3 / n-6$ & $1.4 \pm 0.2$ & $1.1 \pm 0.1$ & $1.2 \pm 0.1$ & $1.3 \pm 0.2$ \\
\hline $22: 6 / 20: 5$ & $18.8 \pm 3.2$ & $14.3 \pm 0.9$ & $14.0 \pm 0.8$ & $11.6 \pm 0.7$ \\
\hline $22: 5 / 20: 4$ & $4.4 \pm 1.2$ & $2.8 \pm 0.5$ & $1.3 \pm 0.0$ & $1.3 \pm 0.0$ \\
\hline Total $\left(\mathrm{fg}\right.$ cell $\left.^{-1}\right)$ & $825.0 \pm 161.4$ & $1940.5 \pm 185.8$ & $3338.3 \pm 167.6$ & $4236.7 \pm 360.7$ \\
\hline
\end{tabular}




\section{Supplementary Table 3}

Fatty acid composition of polar lipids (expressed wt $\%$ of total FA in polar lipid fraction \pm S.D., $n=3$ ) of $\mathbf{T}$ $=$ Tisochrysis lutea - standard type grown under N-replete $(\mathrm{N})$ and N-reduced conditions (N1/2) on day 4 and day 10. $\sum$ SFA: Total saturated fatty acids; $\sum$ MUFA: Total monounsaturated fatty acids; $\sum$ PUFA: Total polyunsaturated fatty acids. Fatty acids representing less than $0.5 \%$ of total fatty acids were excluded from the list.

\begin{tabular}{|c|c|c|c|c|}
\hline & \multicolumn{2}{|c|}{ Day 4} & \multicolumn{2}{|c|}{ Day 10} \\
\hline & $\mathrm{N}$ & $\mathrm{N} 1 / 2$ & $\mathrm{~N}$ & $\mathrm{~N} 1 / 2$ \\
\hline $14: 0$ & $17.8 \pm 1.2$ & $12.7 \pm 0.4$ & $14.7 \pm 0.8$ & $10.8 \pm 0.2$ \\
\hline $16: 0$ & $12.7 \pm 0.4$ & $12.7 \pm 0.2$ & $11.2 \pm 0.6$ & $12.2 \pm 0.6$ \\
\hline $16: 1 n-9$ & $0.5 \pm 0.1$ & $0.5 \pm 0.0$ & $0.5 \pm 0.1$ & $0.5 \pm 0.0$ \\
\hline $16: 1 n-7$ & $3.4 \pm 0.1$ & $2.8 \pm 0.1$ & $3.6 \pm 0.1$ & $3.0 \pm 0.1$ \\
\hline $18: 1 n-9$ & $11.5 \pm 0.4$ & $11.6 \pm 0.2$ & $11.3 \pm 0.7$ & $11.7 \pm 0.4$ \\
\hline $18: 1 n-7$ & $2.3 \pm 0.2$ & $2.4 \pm 0.2$ & $2.9 \pm 0.3$ & $2.3 \pm 0.1$ \\
\hline $16: 2 n-4$ & $0.7 \pm 0.0$ & $0.6 \pm 0.0$ & $0.9 \pm 0.0$ & $0.7 \pm 0.0$ \\
\hline $18: 2 n-6$ & $3.1 \pm 0.1$ & $3.8 \pm 0.1$ & $2.1 \pm 0.1$ & $2.4 \pm 0.1$ \\
\hline $18: 3 n-3$ & $6.9 \pm 0.3$ & $5.7 \pm 0.5$ & $4.5 \pm 0.2$ & $4.2 \pm 0.2$ \\
\hline $18: 4 n-3$ & $17.0 \pm 1.4$ & $18.6 \pm 0.7$ & $20.4 \pm 1.5$ & $18.4 \pm 1.2$ \\
\hline $18: 5 n-3$ & $3.4 \pm 0.2$ & $2.7 \pm 0.2$ & $2.2 \pm 0.2$ & $1.5 \pm 0.0$ \\
\hline $20: 5 n-3$ & $0.5 \pm 0.0$ & $0.5 \pm 0.0$ & $0.3 \pm 0.0$ & $0.3 \pm 0.1$ \\
\hline $21: 5 n-3$ & $0.1 \pm 0.0$ & $0.4 \pm 0.1$ & $0.6 \pm 0.0$ & $1.0 \pm 0.2$ \\
\hline $22: 5 n-6$ & $2.1 \pm 0.1$ & $2.9 \pm 0.3$ & $2.4 \pm 0.2$ & $3.3 \pm 0.1$ \\
\hline $22: 5 n-3$ & $0.2 \pm 0.0$ & $0.7 \pm 0.2$ & $0.2 \pm 0.0$ & $0.6 \pm 0.0$ \\
\hline $22: 6 n-3$ & $13.0 \pm 0.3$ & $16.3 \pm 1.4$ & $17.7 \pm 0.4$ & $21.0 \pm 0.4$ \\
\hline$\sum$ SFAs & $31.3 \pm 1.6$ & $26.3 \pm 0.7$ & $26.7 \pm 1.3$ & $24.4 \pm 1.1$ \\
\hline$\sum$ MUFAs & $19.0 \pm 0.7$ & $18.3 \pm 0.7$ & $19.3 \pm 1.0$ & $18.7 \pm 0.7$ \\
\hline$\sum n-9$ & $12.1 \pm 0.3$ & $12.2 \pm 0.3$ & $12.0 \pm 0.8$ & $12.9 \pm 0.8$ \\
\hline$\sum \mathrm{n}-7$ & $6.3 \pm 0.3$ & $5.6 \pm 0.3$ & $6.9 \pm 0.3$ & $5.5 \pm 0.1$ \\
\hline$\sum$ PUFAs & $49.3 \pm 2.2$ & $55.1 \pm 0.9$ & $53.5 \pm 2.3$ & $56.5 \pm 1.0$ \\
\hline$\sum n-4$ & $0.9 \pm 0.1$ & $0.7 \pm 0.0$ & $1.0 \pm 0.0$ & $0.8 \pm 0.0$ \\
\hline$\sum \mathrm{n}-6$ & $6.3 \pm 0.2$ & $8.0 \pm 0.5$ & $5.6 \pm 0.2$ & $6.8 \pm 0.3$ \\
\hline$\sum n-3$ & $41.5 \pm 2.1$ & $45.7 \pm 0.9$ & $46.1 \pm 2.2$ & $47.5 \pm 1.4$ \\
\hline$n-3 / n-6$ & $6.6 \pm 0.2$ & $5.7 \pm 0.4$ & $8.3 \pm 0.5$ & $7.0 \pm 0.5$ \\
\hline $22: 6 / 20: 5$ & $23.8 \pm 0.9$ & $31.8 \pm 2.1$ & $68.0 \pm 3.9$ & $70.6 \pm 17.7$ \\
\hline $22: 5 / 20: 4$ & $15.5 \pm 4.3$ & $20.6 \pm 2.0$ & $14.1 \pm 2.1$ & $11.8 \pm 1.8$ \\
\hline Total fg cell ${ }^{-1}$ & $1228.3 \pm 53.9$ & $991.1 \pm 55.1$ & $1006.5 \pm 34.5$ & $834.7 \pm 73.1$ \\
\hline
\end{tabular}




\section{Supplementary Table 4}

Fatty acid composition of polar lipids (expressed wt\% of total FA in polar lipid fraction \pm S.D., $n=3$ ) of $\mathbf{T}+=$ Tisochrysis lutea - selected strain grown under N-replete $(\mathrm{N})$ and N-reduced conditions (N1/2) on day 4 and day 10. $\sum$ SFA: Total saturated fatty acids; $\sum$ MUFA: Total monounsaturated fatty acids; $\sum$ PUFA: Total polyunsaturated fatty acids. Fatty acids representing less than $0.5 \%$ of total fatty acids were excluded from the list.

\begin{tabular}{|c|c|c|c|c|}
\hline & \multicolumn{2}{|c|}{ Day 4} & \multicolumn{2}{|c|}{ Day 10} \\
\hline & $\mathrm{N}$ & $\mathrm{N} 1 / 2$ & $\mathrm{~N}$ & $\mathrm{~N} 1 / 2$ \\
\hline $14: 0$ & $18.1 \pm 1.5$ & $20.9 \pm 0.4$ & $19.1 \pm 0.4$ & $21.3 \pm 0.6$ \\
\hline $16: 0$ & $8.3 \pm 0.3$ & $9.9 \pm 0.2$ & $10.5 \pm 0.2$ & $11.9 \pm 0.4$ \\
\hline $16: 1 n-9$ & $0.5 \pm 0.0$ & $0.7 \pm 0.2$ & $0.5 \pm 0.1$ & $0.4 \pm 0.0$ \\
\hline $16: 1 n-7$ & $2.1 \pm 0.1$ & $2.0 \pm 0.1$ & $2.1 \pm 0.0$ & $2.2 \pm 0.0$ \\
\hline $18: 1 n-9$ & $12.0 \pm 0.2$ & $14.3 \pm 0.3$ & $14.4 \pm 0.2$ & $16.8 \pm 0.3$ \\
\hline $18: 1 n-7$ & $2.1 \pm 0.0$ & $2.4 \pm 0.3$ & $2.8 \pm 0.3$ & $2.7 \pm 0.1$ \\
\hline $16: 2 n-4$ & $0.5 \pm 0.0$ & $0.5 \pm 0.0$ & $0.4 \pm 0.0$ & $0.4 \pm 0.0$ \\
\hline $18: 2 n-6$ & $4.1 \pm 0.3$ & $3.6 \pm 0.1$ & $4.0 \pm 0.1$ & $4.1 \pm 0.1$ \\
\hline $18: 3 n-6$ & $0.5 \pm 0.1$ & $0.4 \pm 0.0$ & $0.1 \pm 0.0$ & $0.1 \pm 0.0$ \\
\hline $18: 3 n-3$ & $6.9 \pm 0.5$ & $5.8 \pm 0.1$ & $6.2 \pm 0.2$ & $5.7 \pm 0.3$ \\
\hline $18: 4 n-3$ & $20.1 \pm 0.1$ & $16.9 \pm 1.0$ & $14.6 \pm 0.5$ & $11.4 \pm 0.8$ \\
\hline $18: 5 n-3$ & $1.4 \pm 0.1$ & $0.9 \pm 0.1$ & $0.7 \pm 0.0$ & $0.5 \pm 0.0$ \\
\hline $20: 5 n-3$ & $0.5 \pm 0.0$ & $0.4 \pm 0.0$ & $0.2 \pm 0.0$ & $0.1 \pm 0.0$ \\
\hline $22: 5 n-6$ & $2.8 \pm 0.2$ & $2.7 \pm 0.2$ & $3.0 \pm 0.1$ & $2.9 \pm 0.0$ \\
\hline $22: 5 n-3$ & $1.0 \pm 0.1$ & $0.2 \pm 0.0$ & $0.4 \pm 0.1$ & $0.2 \pm 0.0$ \\
\hline $22: 6 n-3$ & $14.5 \pm 0.9$ & $14.0 \pm 0.5$ & $14.4 \pm 0.4$ & $14.4 \pm 0.6$ \\
\hline$\sum$ SFAs & $27.1 \pm 1.2$ & $31.5 \pm 0.6$ & $31.1 \pm 0.4$ & $34.2 \pm 0.9$ \\
\hline$\sum$ MUFAs & $17.7 \pm 0.1$ & $20.6 \pm 0.1$ & $20.9 \pm 0.5$ & $22.8 \pm 0.2$ \\
\hline$\sum n-9$ & $12.5 \pm 0.2$ & $15.1 \pm 0.4$ & $15.0 \pm 0.2$ & $17.2 \pm 0.3$ \\
\hline$\sum n-7$ & $4.8 \pm 0.2$ & $5.1 \pm 0.3$ & $5.4 \pm 0.3$ & $5.2 \pm 0.1$ \\
\hline$\sum$ PUFAs & $54.6 \pm 1.3$ & $47.0 \pm 0.5$ & $46.8 \pm 0.7$ & $41.6 \pm 1.0$ \\
\hline$\sum n-4$ & $0.6 \pm 0.0$ & $0.6 \pm 0.0$ & $0.4 \pm 0.0$ & $0.4 \pm 0.0$ \\
\hline$\sum n-6$ & $8.4 \pm 0.3$ & $7.5 \pm 0.2$ & $8.3 \pm 0.2$ & $8.1 \pm 0.2$ \\
\hline$\sum n-3$ & $44.8 \pm 1.0$ & $38.5 \pm 0.7$ & $37.0 \pm 1.0$ & $32.8 \pm 0.8$ \\
\hline$n-3 / n-6$ & $5.4 \pm 0.1$ & $5.2 \pm 0.2$ & $4.4 \pm 0.2$ & $4.1 \pm 0.1$ \\
\hline $22: 6 / 20: 5$ & $27.0 \pm 2.5$ & $35.8 \pm 4.0$ & $60.1 \pm 10.2$ & $101.9 \pm 13.0$ \\
\hline $22: 5 / 20: 4$ & $17.9 \pm 0.3$ & $18.2 \pm 5.7$ & $12.3 \pm 1.7$ & $10.7 \pm 2.5$ \\
\hline Total fg cell ${ }^{-1}$ & $1295.9 \pm 43.1$ & $1308.9 \pm 45.8$ & $1203.0 \pm 125.3$ & $1172.4 \pm 76.4$ \\
\hline
\end{tabular}

